\title{
Sensitivity Study of a Dynamic Thermodynamic Sea Ice Model
}

\author{
David M. Holland, Lawrence A. Mysak, and Davinder K. ManaK ${ }^{1}$ \\ Centre for Climate and Global Change Research and Department of Atmospheric and Oceanic Sciences, \\ McGill University, Montréal, Québec, Canada
}

JOSEF M. OBERHUBER

Meteorology Institute, University of Hamburg, Hamburg, Germany

\begin{abstract}
A numerical simulation of the seasonal sea ice cover in the Arctic Ocean and the Greenland, Iceland, and Norwegian seas is presented. The sea ice model is extracted from Oberhuber's (1990) coupled sea ice-mixed layer-isopycnal general circulation model and is written in spherical coordinates. The advantage of such a model over previous sea ice models is that it can be easily coupled to either global atmospheric or ocean general circulation models written in spherical coordinates. In this model, the thermodynamics are a modification of that of Parkinson and Washington (1979), while the dynamics use the full Hibler (1979) viscous-plastic rheology. Monthly thermodynamic and dynamic forcing fields for the atmosphere and ocean are specified. The simulations of the seasonal cycle of ice thickness, compactness, and velocity, for a control set of parameters, compare favorably with the known seasonal characteristics of these fields. A sensitivity study of the control simulation of the seasonal sea ice cover is presented. The sensitivity runs are carried out under three different themes, namely, numerical conditions, parameter values, and physical processes. This last theme refers to experiments in which physical processes are either newly added or completely removed from the model. Approximately $\mathbf{8 0}$ sensitivity runs have been performed in which a change from the control run environment has been implemented. Comparisons have been made between the control run and a particular sensitivity run based on time series of the seasonal cycle of the domain-averaged ice thickness, compactness, areal coverage, and kinetic energy. In addition, spatially varying fields of ice thickness, compactness, velocity, and surface temperature for each season are presented for selected experiments. A brief description and discussion of the more interesting experiments are presented. The simulation of the seasonal cycle of Arctic sea ice cover is shown to be robust.
\end{abstract}

\section{INTRODUCTION}

Sea ice plays an important role in the behavior and modeling of the Earth's climate system. For example, it serves as a highly insulating and reflective boundary layer between the atmosphere and the ocean. Thus, it is capable of profoundly modulating atmosphere-ocean interaction at high latitudes. It is for this reason that sea ice models are presently coupled to global atmospheric and ocean general circulation models in climate studies. The purpose of this report is to study thoroughly the sea ice component of the climate system in isolation, in a form recently introduced by Oberhuber [1990].

In this study an uncoupled dynamic thermodynamic sea ice model of the Arctic sea ice cover is run for a variety of parameters to an equilibrium seasonal cycle using prescribed atmospheric and oceanic forcing. The model is fully described in a report by Holland et al. [1991a]. In brief, Oberhuber [1990] solves similar sea ice equations as in Hibler [1979]; however, Oberhuber introduces a new numerical scheme for the equations and solves them on a spherical grid. A broad spectrum of sensitivity studies are carried out on the parameters which characterize the sea ice physics. Also, experiments are performed on the various atmospheric and oceanic forcing fields used to drive the uncoupled model. The aim of this study is to identify the relative

\footnotetext{
${ }^{1}$ Now at Canada Centre for Remote Sensing, Ottawa, Ontario.

Copyright 1993 by the American Geophysical Union.

Paper number 92JC02015. 0148-0227/93/92JC-02015\$05.00
}

importance of each process in the model. The results should help modelers identify those aspects of sea ice physics that need to be improved in the present generation of global climate models.

Previous sensitivity studies include the pioneering work of Maykut and Untersteiner [1971], who provided a rather complete and detailed description of a one-dimensional thermodynamic sea ice model. This was followed by Semtner [1976], who simplified the Maykut and Untersteiner thermodynamics without compromising model performance. Semtner also provided an analysis of the sensitivity of his model to various changes. However, these models ignore both the three-dimensional extent of sea ice and ice dynamics. The model sensitivity results found in these studies are not always valid in a three-dimensional sense, as will be seen in this report. Studies by Parkinson and Washington [1979] and by Hibler [1979] introduced both the three-dimensionality and the dynamics of sea ice. Some sensitivity analyses of the models were carried out. The coupling of a dynamic thermodynamic sea ice model to an ocean general circulation model has been carried out by Hibler and Bryan [1987] and Semtner [1987]. Fleming [1990] has investigated the sensitivity of a coupled sea ice-ocean model to various parameters and mechanisms. To the best of the authors' knowledge, no sensitivity studies have been carried out on sea ice models incorporated into fully coupled atmosphere-oceansea ice models.

It is difficult to evaluate the relative importance of the sensitivity results reported above because they each use different sea ice models. In this study we repeat many previous sensitivity studies and also carry out many new 
experiments, all in a controlled environment. This allows comparison of each sensitivity experiment result to a basic control run simulation. Each sensitivity experiment is performed by changing only one condition, parameter, or process from the control run environment. This places each individual sensitivity experiment in a context where it can be confidently compared and related to the other sensitivity experiments conducted here.

The major limitation of this study is that it does not allow for a sensitivity analyses of the important feedback processes that occur in a completely coupled atmosphereocean-sea ice model. One barrier to such an investigation is not only the immense computing effort required but also the manyfold increase in the number of sensitivity analyses envisaged. The number of degrees of freedom in such a system include not only those of the individual components but also those representing the interactions and feedbacks between components. Nevertheless, such work is of fundamental importance and will serve as an important aid in interpreting the simulations created by such models.

In this study, the sensitivity of the sea ice model to a particular change is gaged by the response of the prognostic output fields of the model. For selected experiments, time series of the equilibrium seasonal cycle of model domainaveraged ice thickness, areal coverage, compactness, and kinetic energy are presented. The control run time series is overlayed in each instance for comparison. A given sensitivity run may impact on some, none, or all of the ice prognostics mentioned above.

The remainder of this paper is organized as follows. Section 2 describes the sea ice model equations and numerical methods. Section 3 presents the control run simulation. Section 4 provides a summary in outline form of all the experiments performed as well as a discussion of the results of the experiments judged to be the most interesting. Section 5 concludes the paper.

\section{Sea ICE Model}

As described by Hibler [1979], the components of the model are a momentum balance which includes numerical diffusion, Coriolis force, sea surface tilt, air and water stresses, and internal ice stress; a constitutive law which relates the internal ice stress to the strain rate (i.e., ice velocity gradients) and the ice strength; an ice strength which is a function of the ice thickness and fraction of open water; a simple ice thickness distribution (consisting of the fraction of open water and the total ice mass) which accounts for the change of compactness and ice thickness due to growth or ablation, advection, and deformation; and an ocean mixed layer which serves as a heat reservoir.

The thermodynamic and dynamic aspects of the model are interrelated because ice motion causes local changes in ice thickness as ice is advected into or out of a region, while changes in ice thickness due to ablation or growth change the ice strength characteristics, which in turn affect the ice motion. On the large scale, ice is exported from the Arctic Ocean through Fram Strait into the Greenland, Iceland, and Norwegian (GIN) seas.

\subsection{Sea Ice Equations}

For the momentum balance the ice is considered to move in a two-dimensional spherical plane with forcing fields operating on the ice via simple planetary boundary layers. The nonlinear inertial terms are neglected. The momentum equation is given by

$$
\frac{\partial \mathrm{u} h}{\partial t}=\nabla \cdot A^{m} \nabla \mathbf{u} h-\mathbf{f} \times \mathbf{u} h-g h \nabla \Gamma+\frac{\tau_{\text {air }}}{\rho_{\text {ice }}}+\frac{\tau_{\text {ocn }}}{\rho_{\text {ice }}}+\frac{\mathbf{I}}{\rho_{\text {ice }}}
$$

where $\mathbf{u}=(u, v)$ is the horizontal ice velocity vector, $h$ the ice floe thickness evenly distributed over a grid cell, $A^{m}$ the horizontal diffusion coefficient for momentum, $f$ the Coriolis vector, $g$ the acceleration due to gravity, $\Gamma$ the sea surface dynamic height, $\tau_{\text {air }}$ the ice stress due to surface winds, $\tau_{o c n}$ the ice stress due to surface ocean currents and bottom drag, $\rho_{\text {ice }}$ the ice density, and I the internal ice force.

Oberhuber [1990] has rewritten Hibler's [1979] momentum balance in a momentum and mass conserving flux form, since the latter provides an easier treatment of the ice edge behavior. This is because the flux $h u$ is a much more well-behaved quantity at the ice edge than is $\mathbf{u}$ alone. Thin ice of low compactness near the ice edge may have large velocities in response to dynamic forcing; however, it is the thinness of the ice itself that makes the ice flux a smoother and more well-behaved quantity than the velocity at the ice margin. Furthermore, this formulation avoids having the advection term $\mathbf{u} \cdot \nabla h$ appear in (1), which can result in undershooting (i.e., negative ice thickness). Both $u$ and $\nabla h$ are large on the ice edge. The formulation in (1) avoids this problem by dealing instead with the term $\nabla \cdot \mathbf{v} h$, which is small at the ice edge.

The ice-cover thickness $h$ is modeled with two idealized ice thickness levels: thick and thin. The cutoff thickness between the two levels is denoted by $h_{0}$. The thin ice is treated as effectively open water and as such represents the presence of leads in the ice. To keep track of these ice thickness levels, a variable called the ice compactness $q$ (also known as the ice concentration) is introduced which is defined as the fraction of a grid cell area covered by thick ice; the rest of the cell is covered by thin ice, which for computational ease is taken to be of zero thickness.

The spatial and temporal variations in thickness and compactness are modeled by the continuity equations

$$
\begin{aligned}
& \frac{\partial h}{\partial t}=-\nabla \cdot \mathbf{u} h+\nabla \cdot A^{s} \nabla h+F_{h}, \\
& \frac{\partial q}{\partial t}=-\nabla \cdot \mathbf{u} q+\nabla \cdot A^{s} \nabla q+F_{q},
\end{aligned}
$$

where $F_{h}$ and $F_{q}$ are thermodynamic forcing or source terms. The numerical diffusion terms for these scalar equations have coefficient $A^{s}$. To ensure that stable solutions are found for $h$ and $q$, it is necessary to include the diffusion term; furthermore, diffusion is justified in that it can be argued to represent the effect of ocean eddies on the ice behavior.

Physical constraints are imposed on these two equations. The thickness equation (2) is constrained such that $h \geq 0$ at all times to avoid negative ice thickness. The compactness equation (3) is constrained such that $0 \leq q \leq q_{\max }$ at all times. The maximum ice compactness $q_{\max }$ cannot physically exceed unity. Setting $q_{\max }$ to some value slightly less than unity ensures that a fraction $\left(1-q_{\max }\right)$ of every grid cell will always be open water. 
The thermodynamic forcing term $F_{h}$ in (2) resulting in ice growth or melt is given as a contribution over the fraction $(1-q)$ of thin ice and the fraction $q$ of thick ice as

$$
F_{h}=-\frac{(1-q) Q_{\text {air }}+q Q_{\text {ice }}+Q_{\text {ocn }}}{\rho_{\text {ice }} L_{f}},
$$

where $Q_{\text {air }}$ is the total atmospheric heat flux at the surface of open water or leads due to solar, longwave, sensible and latent heating, $Q_{\text {ice }}$ is the conductive heat flux through the ice into the ocean, $Q_{\text {ocn }}$ is the oceanic heat flux supplied to the oceanic mixed layer from the deep ocean due to advective and convective processes, and $L_{f}$ the latent heat of fusion of water. The sign convention for $F_{h}$ is such that a positive value indicates a source term for ice growth in (2). In such an instance the ice is losing heat.

The forcing function for the ice compactness $F_{q}$ in (3) is of the same sign as the thickness term $F_{h}$. This means that when the ice is growing, corresponding to $F_{h}$ positive, then the ice compactness is simultaneously increasing and vice versa. The exact relation between $F_{h}$ and $F_{q}$ is given by

Freezing

$$
F_{q}=C_{\text {frez }} \frac{F_{h}}{h_{0}}(1-q) \quad F_{h}>0
$$

Melting

$$
F_{q}=C_{\text {melt }} \frac{F_{h}}{2 h} q \quad F_{h}<0
$$

Recall $h_{0}$ is the cutoff thickness between the thick and thin ice. The two empirical coefficients $C_{\text {frez }}$ and $C_{\text {melt }}$ determine the relative rates at which the ice compactness increases and decreases, respectively. The model is more sensitive to $C_{\text {frez }}$ than $C_{\text {melt }}$ as the growth of thin ice under freezing conditions is a more rapid process than the melting of thick ice under thawing conditions.

Beneath the ice an ocean mixed layer forces changes in the ice both thermodynamically, through an ocean heat flux, and dynamically through an ocean current stress and a surface tilt. The mixed layer currents do not advect heat laterally as the oceanic forcing is diagnostic. The ocean mixed layer is of uniform depth and of constant heat capacity. The temperature and salinity are uniform throughout the vertical extent of the mixed layer, though they vary both horizontally and in time. The ocean density is uniform everywhere and equal to a constant in a Boussinesq sense. Horizontal variations in density are not important as the ocean currents are specified. Furthermore, vertical variations in density are not important as convective overturning is implicitly specified.

\subsection{Numerical Methods}

The equations for sea ice momentum, thickness, and compactness are solved on a spherical grid in finite difference form using a semiimplicit time step scheme combined with a predictor-corrector scheme. The predictor step for the ice thickness (see (2)) treats the divergence of the ice thickness flux explicitly. The corrector step for the ice thickness treats the diffusion term implicitly. The same procedure applies to the compactness (see (3)). The predic- tor step for the momentum equation (1) treats the stresses and Coriolis force implicitly. The corrector step for (3) treats the rheology and momentum diffusion implicitly. A point of fundamental importance to recognize is that the implicit treatment of the momentum diffusion in this manner produces smooth momentum fluxes. This allows for the explicit treatment of the divergence of ice thickness and compactness at the next time step.

The equations for ice momentum, thickness, and compactness are discretized in space using a centered finite difference approach. In time, the equations are integrated using an Euler-implicit scheme in which terms are averaged between the old and the new time level. No-slip boundary conditions are applied for momentum.

The numerical grid is in spherical coordinates with grid points every $3^{\circ}$ of longitude and every $1^{\circ}$ of latitude; thus the east-west resolution increases towards the North Pole. An important aspect of the numerical technique employed by Oberhuber [1990] is that he only iterates the solution in a north-south direction. As the grid spacing is uniform in this direction, the problem of a converging grid spacing is avoided. There is, however, grid convergence in the eastwest direction as one increases in latitude. Solving the equations using a direct (i.e., noniterative) solver at each latitude circle allows one to avoid the problem of converging grid spacing. In effect, the equations are solved directly in the east-west direction at each latitude circle while they are iterated in the north-south direction. The model domain extends in latitude from $65^{\circ} \mathrm{N}$ to the North Pole. Although Baffin Bay and the Canadian Archipelago are within the model domain, they are not modeled here. Baffin Bay is not considered to have a direct impact on the sea ice in the Arctic Ocean or the GIN seas. An ocean-land mask is placed over the spherical grid such that any grid point corresponding to a geographical position in either the Arctic Ocean or the GIN seas is masked as an ocean point and as such is permitted to have sea ice. All other points on the grid are masked as land points and do not enter into the computations.

The numerical scheme is not fully implicit and thus there exists a finite limit on the time step $\delta t$ due to stability requirements. Although derived for explicit schemes, the Courant condition [Press et al., 1988] gives an indication of the maximum value of $\delta t$ for this semiimplicit scheme. This condition states that one must be able to resolve the fastest propagating quantity modeled on a numerical grid. In this instance, the fastest moving quantity is the advection of the ice, which has a characteristic velocity of the order of 10 $\mathrm{cm} / \mathrm{s}$. The fastest resolvable speed on the numerical grid is the ratio of $\delta \lambda$ to $\delta t$, where $\delta \lambda$ is a characteristic longitudinal grid spacing, which is variable on a spherical grid. It turns out that it is the minimum grid spacing that controls the fastest resolvable speed. Near the North Pole, the spherical grid has a minimum spacing of $5 \mathrm{~km}$. Applying the Courant condition, the maximum time step is

$$
\delta t<\frac{\delta \lambda}{u} \approx 13 \text { hours }
$$

Thus the choice of time step is taken to be $1 / 2$ day.

The model is run on a Cray X-MP computer. One year of computer simulation requires approximately $6 \mathrm{~min}$ of computing time on the Cray. The greatest fraction of the com- 
puting effort (80\%) is spent on ice dynamics, as opposed to the thermodynamics. The code has been optimized by $O$ berhuber [1990] and runs at a rate of just over 100 megaflops. Overall, the computing requirements are extremely modest in comparison to the requirements of an atmospheric or an ocean general circulation model for 1 year of simulation. Given the importance of the ice cover to atmosphere-ocean interaction, the use of a dynamic thermodynamic sea-ice model written in spherical coordinates with a viscous-plastic rheology is justified in coupled climate models.

A no-slip boundary condition for ice velocities is used along coastlines. The no-slip condition is also used at open boundaries where the Arctic Ocean or the GIN seas would normally exchange sea ice with other ocean basins. Thus, there is no ice transport through the Bering Strait, the Canadian Archipelago, the Denmark Strait, or the passage between Iceland and Norway.

The mapping of the spherical grid onto a rectangular computer array introduced an artificial boundary along the meridian $180^{\circ} \mathrm{E}$. A cyclic boundary condition was used for velocity, thickness, and compactness along this meridian.

At the pole a no-slip condition was used for velocity. This is analogous to placing a stick at the North Pole. A more complex boundary formulation is possible at the pole whereby the ice would be allowed to freely pass over the North Pole. Such a formulation was not included in the control run simulation. Nevertheless, the use of a no-slip condition at the pole is felt to be justified, as this is an advection problem and not a wave-type problem, whereby wave reflections at the pole would be important. The boundary conditions for thickness and compactness over the pole are reasonable, as they simply ensure that thickness and compactness are continuous there.

Both the vector momentum equation and the scalar thickness and compactness equations include numerical diffusion. For the momentum equation the coefficient is $A^{m}$ (see (1)), while for the scalar equations it is $A^{s}$ (see (2) and (3)). Numerical diffusion is included to eliminate the nonphysical two grid point computational mode which may be present when centered spatial finite differences are used. Furthermore, the justification for these coefficients is the eddies in the ocean which redistribute the ice due to the ice-ocean drag. The requirement for computational stability in an explicit scheme [Roach, 1985] in that the computational cell Reynold's number $R_{e}$ satisfies the inequality

$$
R_{e} \equiv \frac{u \delta \lambda}{A} \ll 2
$$

where $u$ is a characteristic ice velocity, $\delta \lambda$ the grid spacing, and $A$ the diffusion coefficient. On a spherical grid with variable grid spacing it is the largest grid spacing which constrains the choice of diffusion coefficient. This is in contrast with the constraint for the time step whereby the smallest grid spacing is the constraint. The largest grid spacing in this instance is $140 \mathrm{~km}$, which occurs along the southern boundary of the domain. Again, a characteristic ice velocity is of order $10 \mathrm{~cm} / \mathrm{s}$. Thus, to satisfy the cell Reynolds number criterion, we require a diffusion coefficient of the order of $7000 \mathrm{~m}^{2} / \mathrm{s}$. However, because we are using an implicit scheme, we are able to get stable solutions for diffusion coefficients of order $2000 \mathrm{~m}^{2} / \mathrm{s}$ (for both $A^{m}$ and $A^{s}$ ). Implicit schemes improve the ability to use smaller
TABLE 1. Numerical Values of Parameters and Constants

\begin{tabular}{|c|c|}
\hline Parameter & Value \\
\hline Velocity diffusion coefficient $A^{m}, \mathrm{~m}^{2} \mathrm{~s}^{-1}$ & 2000 \\
\hline Earth's angular velocity $\Omega, s^{-1}$ & $7.292 \times 10^{-5}$ \\
\hline Gravity $g, \mathrm{~m} \mathrm{~s}^{-2}$ & 9.806 \\
\hline Ice density $\rho_{\text {ice }}, \mathrm{kg} \mathrm{m}^{-3}$ & 910 \\
\hline Earth radius $r, \mathrm{~km}$ & 6400 \\
\hline Air density $\rho_{\text {air }}, \mathrm{kg} \mathrm{m}^{-3}$ & 1.2 \\
\hline Air drag coefficient, $C_{\text {air }}$ & 0.0012 \\
\hline Water density $\rho_{\text {ocn }} \mathrm{kg} \mathrm{m}^{-3}$ & 1025 \\
\hline Water drag coefficient $C_{\text {ocn }}$ & 0.0055 \\
\hline Yield curve eccentricity $e$ & 2 \\
\hline Ice strength $P^{*}, \mathrm{~N} \mathrm{~m}^{-3}$ & 10,000 \\
\hline Decay constant $C^{*}$ & 10 \\
\hline Grid spacing $\delta \lambda, \mathrm{km}$ & $5-140$ \\
\hline Grid spacing, $\delta \phi, \mathrm{km}$ & 111 \\
\hline Scalar diffusion coefficient $A^{s}, \mathrm{~m}^{2} \mathrm{~s}^{-1}$ & 2000 \\
\hline Latent heat fusion $L_{f}, \mathrm{~J} \mathrm{~kg}^{-1}$ & $3.34 \times 10^{5}$ \\
\hline $\begin{array}{l}\text { Specific heat capacity of ice } C_{p \text { ice }} \text {, } \\
\mathrm{J} \mathrm{kg}^{-1} \mathrm{~K}^{-1}\end{array}$ & 0 \\
\hline Ice conductivity $\kappa_{\text {ice }}, \mathrm{W} \mathrm{m}^{-1} \mathrm{~K}^{-1}$ & 2 \\
\hline Ice albedo $\alpha_{\text {ice }}$ & 0.40 \\
\hline Ocean albedo $\alpha_{\text {ocn }}$ & 0.17 \\
\hline Emissivity ice surface $\varepsilon_{\text {sce }}$ & 0.97 \\
\hline Emissivity ocean surface $\varepsilon_{\text {ocn }}$ & 0.97 \\
\hline Stefan-Boltzmann constant $\sigma, \mathrm{W} \mathrm{m}^{-2} \mathrm{~K}^{-4}$ & $5.67 \times 10^{-8}$ \\
\hline Sensible heat coefficient $C_{\text {sens }}$ & 0.0015 \\
\hline Latent heat coefficient $C_{\text {lat }}$ & 0.0015 \\
\hline Cloud fraction $C_{f}$ & 0.85 \\
\hline Specific heat air $C_{p, \text { air }}, \mathrm{J} \mathrm{kg}^{-1} \mathrm{~K}^{-1}$ & 1005 \\
\hline Surface air pressure $p_{\text {surf }}, \mathrm{Pa}$ & $10^{5}$ \\
\hline Latent heat evaporation $L_{e}, \mathrm{~J} \mathrm{~kg}^{-1}$ & $2.5 \times 10^{6}$ \\
\hline Cutoff ice thickness $h_{o}, \mathrm{~m}$ & 0.5 \\
\hline Coefficient of freezing $C_{\text {frez }}$ & 1 \\
\hline Coefficient of melting $C_{\text {melt }}$ & 1 \\
\hline Maximum ice compactness $q_{\max }, \%$ & 100 \\
\hline Mixed layer depth $h_{\text {ocn }}, \mathrm{m}$ & 30 \\
\hline $\begin{array}{l}\text { Specific heat of ocean water } C_{p} \text {, ocn, } \\
\mathrm{J} \mathrm{kg}^{-1} \mathbf{K}^{-1}\end{array}$ & 3930 \\
\hline Time step increment $\delta t$, day & $1 / 2$ \\
\hline Total integration time, years & 10 \\
\hline
\end{tabular}

diffusion coefficients over other schemes because of better phase advection properties in the nonlinear terms.

As in Hibler [1979], mass is conserved for the diffusion terms by setting the diffusion coefficient to zero along the boundaries. As velocity is also zero on the boundaries, mass is conserved for the incompressible portion of the velocity field [Hibler, 1979].

The various atmospheric and oceanographic fields used to force the sea ice model are discussed by Holland et al. [1991a]. All fields are monthly varying with the exception of salinity, which is seasonal. All fields are interpolated onto the model's spherical grid. The fields are interpolated to daily values using simple weighted linear interpolation from values for neighboring months. High-frequency fluctuations due to synoptic-scale atmospheric activity are not present.

A summary of all the values used for the various physical constants and model parameters is presented in Table 1.

\section{Control Run Simulation}

The sea ice model was integrated for a 10-year period from an initial state of ice of zero thickness and no motion. The mixed layer temperature was set close to the freezing temperature $\left(-1.8^{\circ} \mathrm{C}\right)$ everywhere. Climatological (seasonal) atmospheric and oceanic forcing fields were repeatedly 


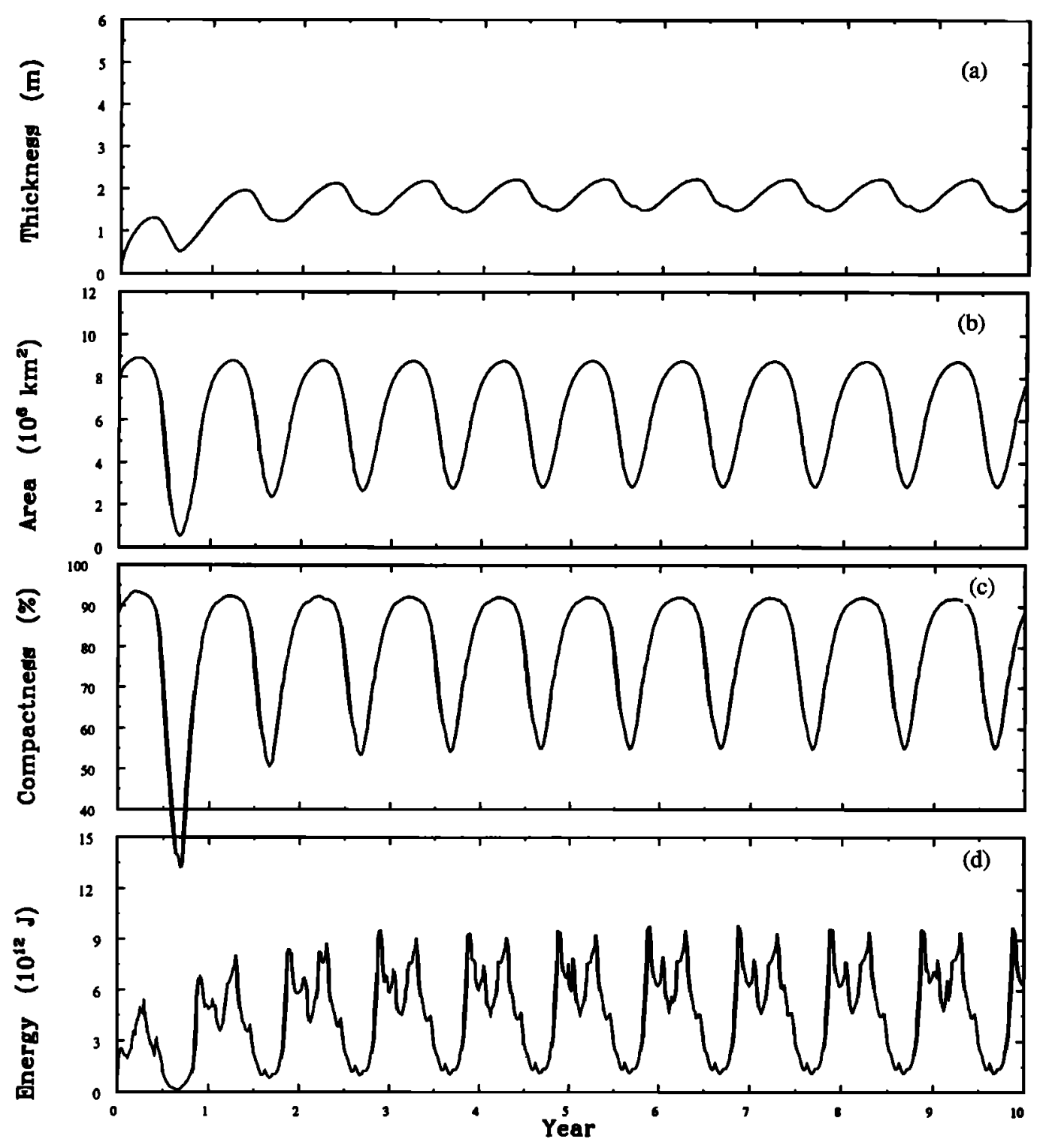

Fig. 1. Time series of effective ice thickness, areal coverage, compactness, and kinetic energy over a 10-year spin-up period. All signals are area averaged over all grid points in the domain that contain ice.

applied for each year of the simulation. Below is a discussion of the control simulation of the various ice characteristics.

Time series of the seasonal variations of the domainaveraged ice thickness, areal coverage, compactness, and kinetic energy (i.e., proportional to mass) over the 10-year period are illustrated in Figure 1. In Figure $1 a$ the effective thickness $h / q$ is presented, as it is more representative of the actual floe thickness than $h$ (which, we recall, is the ice thickness evenly distributed over a grid cell). The time series shows the variations of the effective ice thickness as the model spins up toward an equilibrium state. The ice areal coverage (Figure $1 b$ ) is defined by adding up the geographical surface area of each grid cell in which ice is present, and weighting each such cell by its compactness. The compactness time series in Figure $1 c$ is defined as the average compactness for all grid cells containing ice. The model quickly approaches its equilibrium state within 5 years of integration for each of these signals. The domain-averaged kinetic energy time series (Figure $1 d$ ) is defined as the sum total of the kinetic energy of each ice floe in all grid cells. It has reached a quasi-equilibrium after 5 years; however, due to the nonlinear ice rheology, it continues to show small perturbations throughout the 10-year simulation.

The time series of the annual cycle of the ice characteristics are presented in Figure 2. This figure illustrates the same ice quantities as in the previous figure except that it focuses on the final year of the simulation. The annual cycle of ice thickness indicates a peak in May of about $2.4 \mathrm{~m}$ and a minimum in October of about $1.5 \mathrm{~m}$, with an average thickness of about $2 \mathrm{~m}$. This average thickness is computed by including leads and open water contributions. This is significantly lower than the generally accepted value of $3 \mathrm{~m}$ for the overall ice thickness. However, as with all of the ice characteristics, parameter values can be tuned within acceptable ranges to produce the desired result. The amplitude of the seasonal cycle is roughly $50 \mathrm{~cm}$, which is in good agreement with observations [Maykut and Untersteiner, 1971]. The seasonal cycle of areal coverage ranges from an 

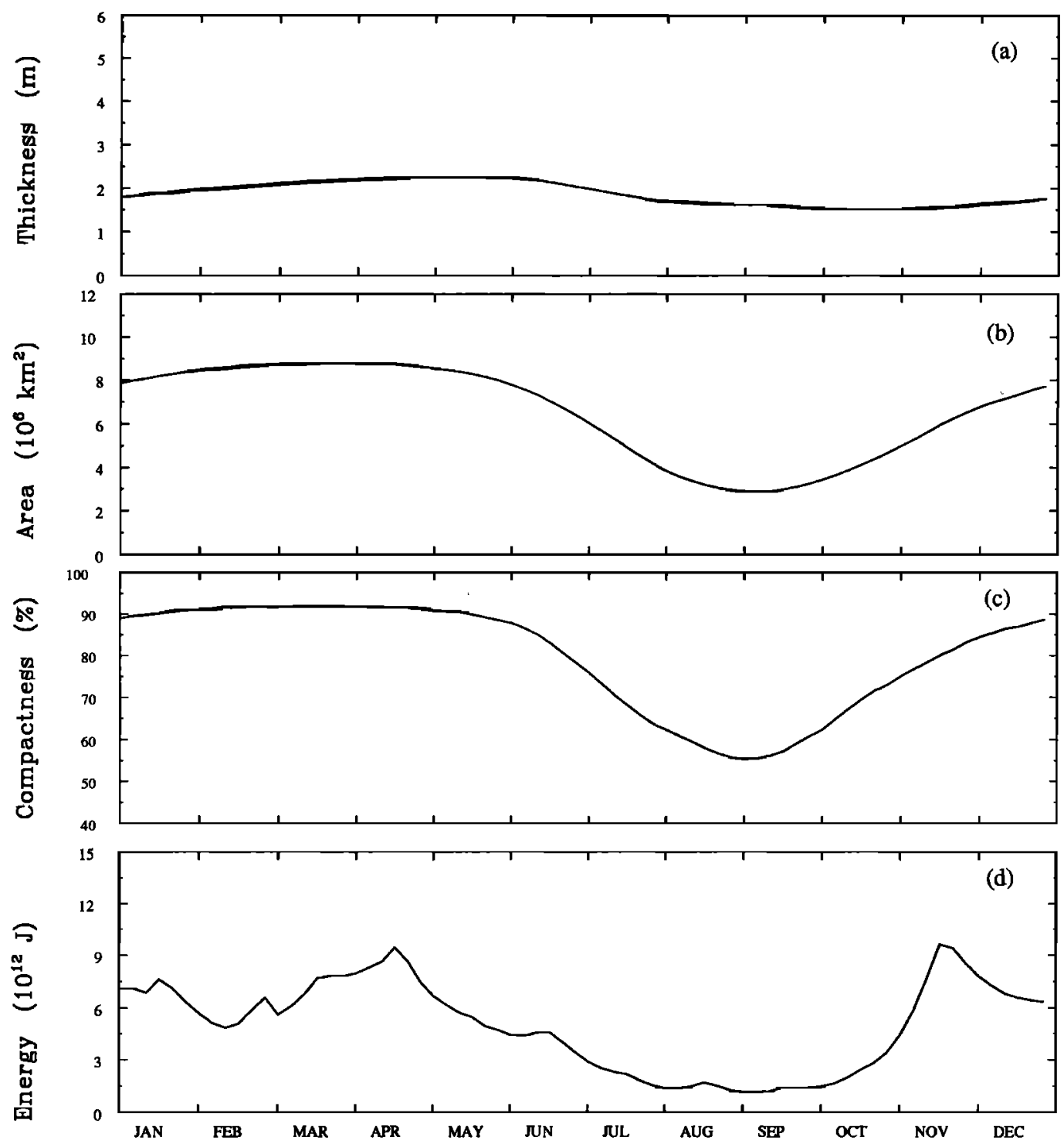

Fig. 2. Time series of effective ice thickness, areal coverage, compactness, and kinetic energy over the equilibrium annual cycle (i.e., over the final year of the spin-up simulation) for the control parameters. All signals are area averaged over all grid points in the domain that contain ice.

April peak of 9 million $\mathrm{km}^{2}$ to a September minimum of 3 million $\mathrm{km}^{2}$. Observations indicate that sea ice varies from a March maximum of about 15 million $\mathrm{km}^{2}$ to a September low of 8 million $\mathrm{km}^{2}$ [Parkinson et al., 1987]. However, these numbers are based on the 20 million $\mathbf{k m}^{2}$ of observed area of sea ice cover in the northern hemisphere. The domain modeled here is a 12 million $\mathbf{~ k m}^{2}$ subset area of that greater domain. Observations indicate that the areal coverage roughly halves during the summer melt season. In the simulation, the summer reduction was to a third of the winter value; thus the amplitude of the seasonal cycle is excessive in the simulation. The seasonal cycle of ice compactness indicates an April maximum greater than $90 \%$ to a September minimum of about $55 \%$. The ice kinetic energy is large during the winter months from November through April, while it is relatively low during the summer months of May through October. The kinetic energy shows prominent peaks both in November and April. These peaks would appear to be related to the ice rheology. For example, the November peak indicates the relatively fast response of low compactness ice pack to increased winter atmospheric forcing. The subsequent decrease in kinetic energy after November may be explained by the increasing ice compactness during the early winter season, a process which hinders ice motion.

The seasonal cycle of the spatial variation of the simulated ice thickness is presented in Figure 3. The cutoff thickness of $50 \mathrm{~cm}$ (shown as heavy line) is used to distinguish the ice pack from the open sea. The results indicate that the greatest ice thickness occurs north of the Canadian Archipelago throughout the seasonal cycle, in good agreement with observations [Bourke and Garrett, 1987].

The seasonal cycle of the spatial variation of the simulated ice compactness is presented in Figure 4. The ice edge (heavy line) is defined as the 1/10th compactness contour. The simulated compactness agrees reasonably well with that as observed by satellite [Parkinson et al., 1987, Figures 4-3 to 4-8]. The compactness remains high along the coastline of the Canadian Archipelago throughout the seasonal cycle. 

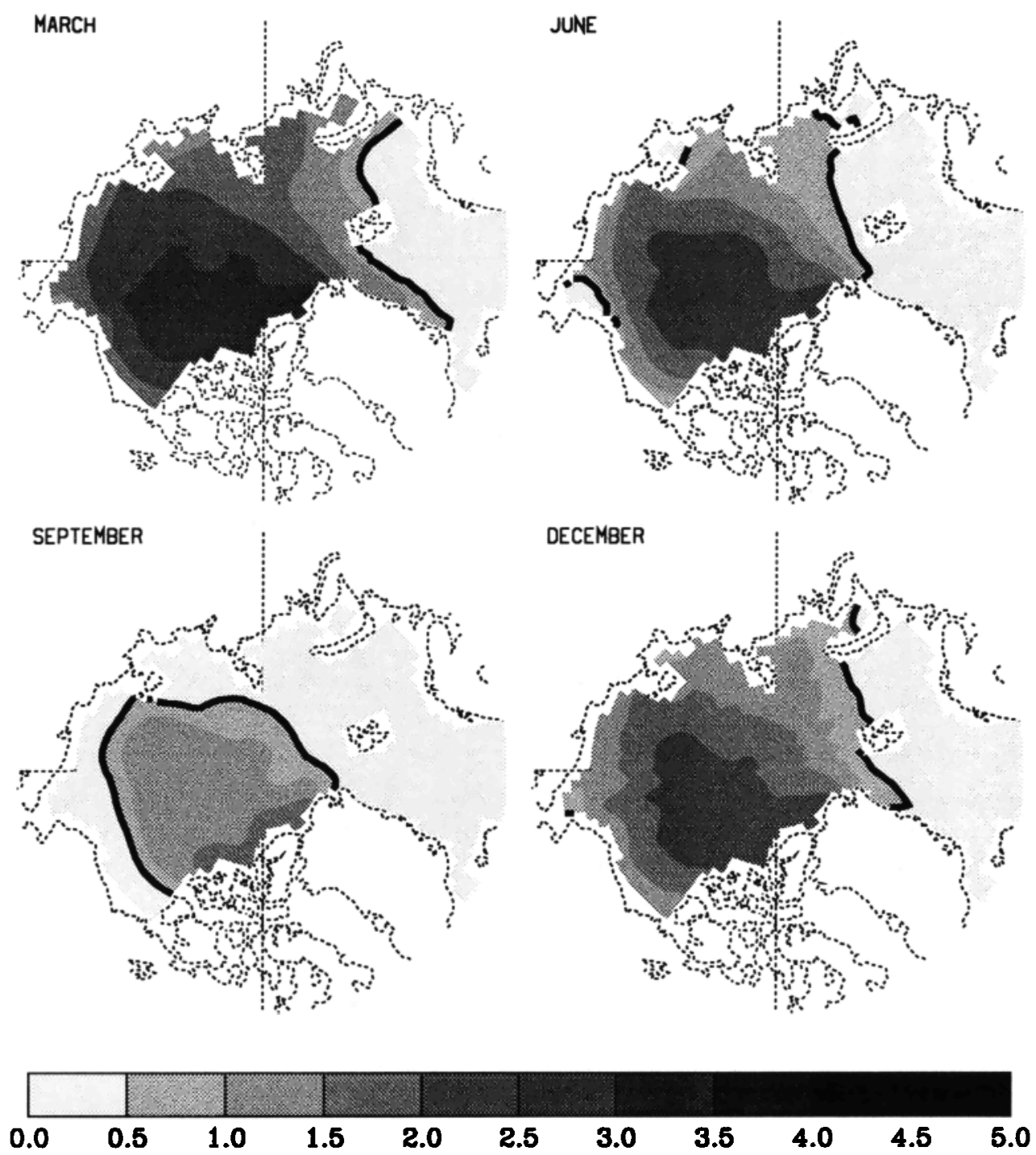

Fig. 3. Seasonally varying ice thickness fields (in units of meters) from the control simulation. The heavy black line indicates the $0.5-\mathrm{m}$ thickness contour.

The observed compactness indicates that the 1/10th contour persists along the Greenland east coast throughout the year, but the simulation has an excessive melt of ice along this coast during summer. There is excessive melt of the ice pack in the central Arctic during summer and early fall as well.

The spatial variation of the simulated ice velocity as presented in Figure 5 reproduces the basic features of Arctic ice drift. There is a strong Beaufort Gyre during winter with velocities of the order of $5 \mathrm{~cm} / \mathrm{s}$ and a slightly weakened gyre in summer. The Beaufort Gyre does not change its sense of rotation throughout the seasonal cycle despite the fact that the atmospheric winds in that region briefly do so in early fall. This is because the ocean currents are also inputing momentum into the ice pack in the form of an anticyclonic gyre in this region. The Transpolar Drift Stream is present, as is a strong ice drift which extends along the Greenland east coast during winter. Ice velocities reach realistic speeds of up to $15 \mathrm{~cm} / \mathrm{s}$. The impact of the no-slip boundary condition at the North Pole can be seen from the ice velocities. Near the pole, the velocities tend to be smaller than elsewhere; however, the boundary condition does not adversely affect the simulation away from the pole. Observed ice drifts [Colony, 1991] based on buoy drift tracks agree well with the drifts simulated here.

The model also produces a prognostic simulation of the ice and ocean surface temperature. Where there is ice, the surface temperature is taken to be a weighted average of the ice surface temperature and the mixed layer temperature of the leads. Where there is no ice, the surface temperature is that of the mixed layer. Figure 6 shows the seasonal cycle of the surface temperature. The heavy line indicates the surface $0^{\circ}$ isotherm. In the central Arctic during winter, surface ice temperatures are less than $-20^{\circ} \mathrm{C}$, which is realistic [Parkinson et al., 1987]. In June the surface temperatures in the central Arctic are spatially uniform (near $0^{\circ} \mathrm{C}$ ) as a result of the summer melt season. A problem with the thermodynamic calculations is illustrated by the surface temperatures along the coast of Norway. Throughout the seasonal cycle these temperatures are too high, being on the order of $15^{\circ} \mathrm{C}$. However, away from the Norwegian coast, these fields compare favorably with those given by Parkinson et al. [1987, Figure 2.5]. 

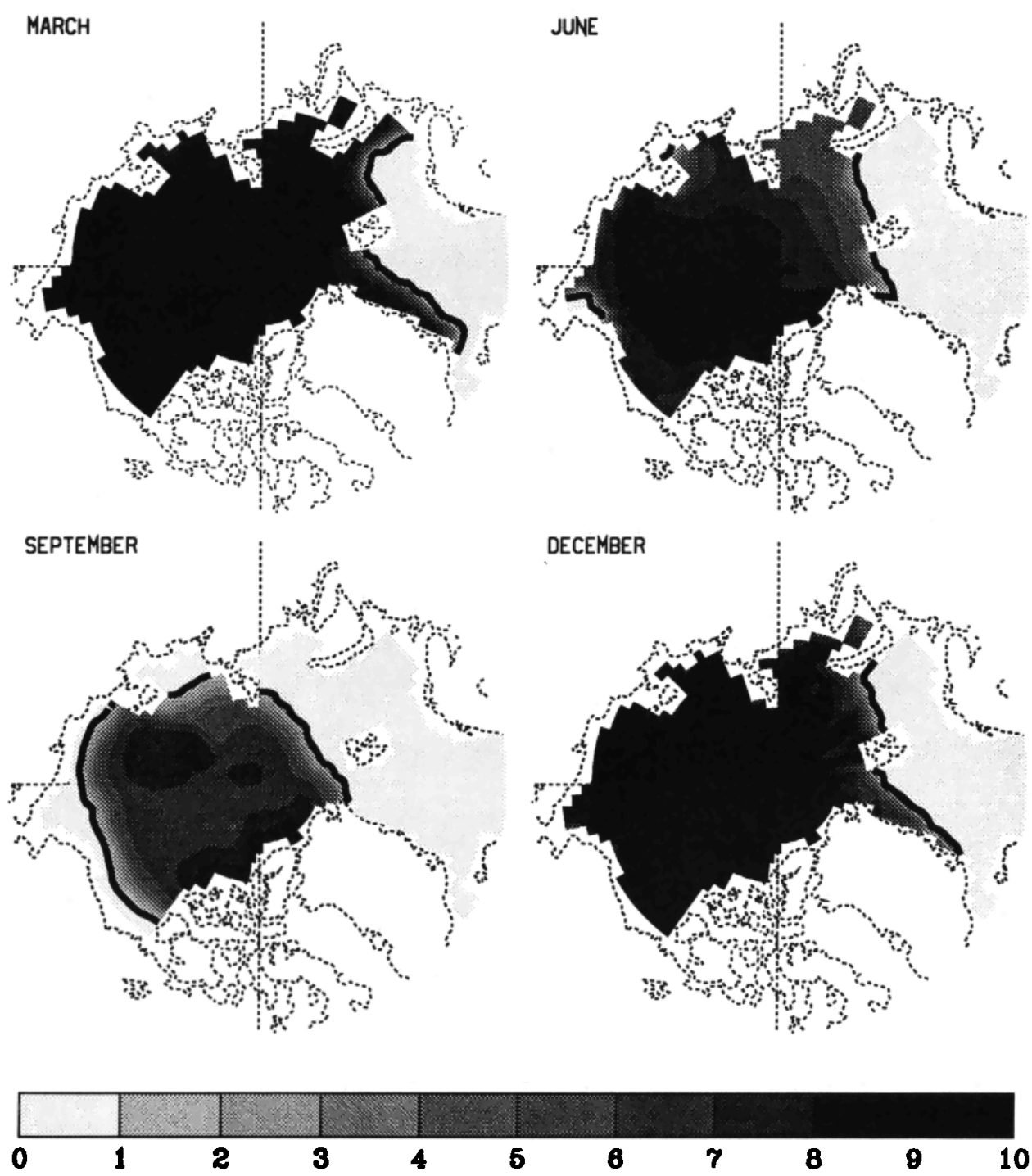

Fig. 4. Seasonally varying ice compactness fields (in units of tenths) from the control simulation. The heavy black line indicates the $1 / 10$ th compactness contour.

\section{SENSITIVITY EXPERIMENTS}

The sensitivity experiments were carried out according to three main themes, namely, numerical conditions, parameter values, and physical processes. The last theme refers to experiments in which physical processes are newly added or completely removed from the model. Tables 2,3 , and 4 , which correspond to the above themes, succinctly indicate the change made in the control run environment in each instance. In each experiment, only a single change was made from the control run computer code. Each sensitivity experiment was integrated for a 10-year period. For each experiment, figures analogous to those of the control run (i.e., Figures 1-6) were produced. The tremendous number of resulting figures prevents their reproduction here; however, they are available in full in a report by Holland et al. [1991b], which also contains a complete discussion of each experiment. In the discussion that follows, only selected sensitivity experiments are discussed.

\subsection{Numerical Conditions (Theme A)}

Experiments Al and A2: time step $\delta t$. A semiimplicit technique is used to integrate the model equations. To avoid numerical instability, a time step of $1 / 2$ day was chosen based on the Courant condition (see (4)).

$A I:$ A reduced time step of 2 hours results in a more energetic ( $>50 \%$ ) winter and springtime ice pack. Spatially, the fields of thickness, compactness, velocity, and surface temperature are smoother for the shorter time step than in the control run, particularly in December.

A2: Using an increased time step of 1 day produces a much less energetic ice pack (50\% decrease in winter). The ice fields show signs of instabilities, particularly in December. An attempt was made to run the model with a time step of 2 days; however, the model became unstable and failed to converge to a solution.

Experiment A10: Boundary condition at North Pole. Since the model is written in spherical coordinates, there is a 

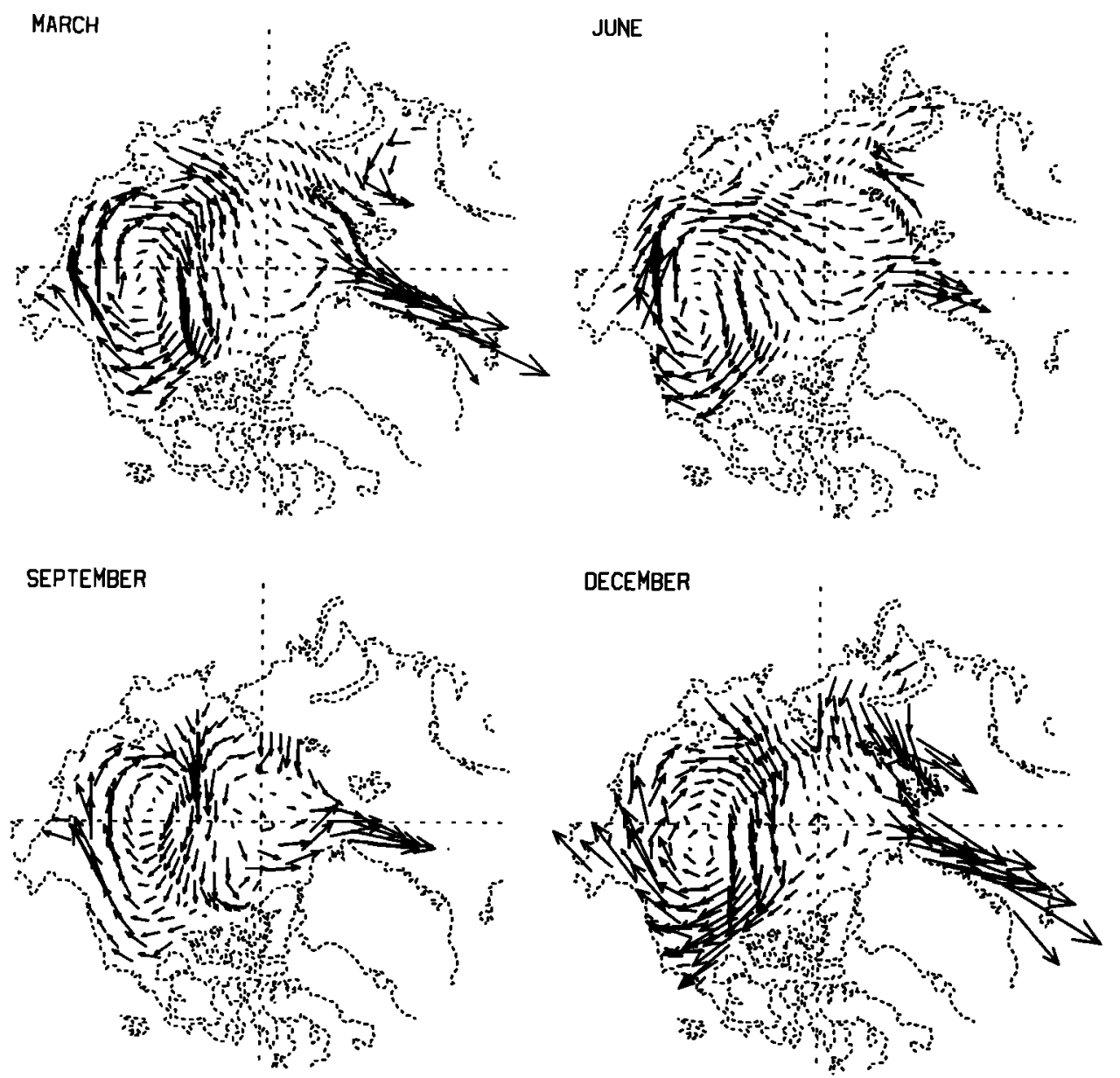

Fig. 5. Seasonally varying ice velocity fields from the control simulation. The largest vector represents an ice velocity
of $15 \mathrm{~cm} / \mathrm{s}$. The main features are the Beaufort Gyre, the Transpolar Drift Stream, and the East Greenland Current Drift.

convergence of the model grid points at the geographic North Pole. Oberhuber [1990] has provided a technique whereby the spherical coordinate grid of the sea ice model may be rotated through Eulerian angles and thus placed outside the modeled domain, to avoid this undesirable convergence of grid cells at the North Pole. However, in fully coupled global atmosphere-ocean-sea ice models, such a rotation is not performed.

The control run used a no-slip boundary condition at the pole. Effectively, this is like placing a stick at the North Pole, since it sets the ice velocity to zero at that grid point. Introducing a more elegant boundary condition whereby the ice is allowed to flow freely over the pole results in little change from the control run (see Figures 7-9). Essentially, the velocity of the ice at the pole is taken to be the vector average of all neighboring velocity points. In overlaying the ice velocity fields from this experiment onto those of the control run, one notes only marginal differences.

Oberhuber [1990] now uses an open-pole boundary condition in his fully coupled global simulations. He finds that the open pole helps to stabilize the model, as quantities are now diffused across the pole. The net effect is that there is now less noise in that region (J. M. Oberhuber, personal communication, 1992).

Recently, Flato and Hibler [1992] have investigated the difficulty of having a singularity at the North Pole. They have written an ice model in spherical coordinates using a cavitating fluid rheology. This formulation of rheology ignores shear stresses. They achieved a good simulation in the vicinity of the pole because the absence of shear stresses in the cavitating fluid formulation allows free slip past an obstruction, such as a stick at the pole. Otherwise, there would be a pronounced thickness buildup there. However, the results here indicate that the original Hibler [1979] formulation of a viscous-plastic rheology, which does include shear stresses, does not lead to pronounced thickness buildup at the pole.

\subsection{Parameter Values (Theme B)}

Experiments $B 7$ and B8: Coefficient of freezing $C_{\mathrm{frez}}$. The forcing term $F_{q}$ for the ice compactness (see (3)) describes the manner in which the ice compactness increases in a given grid cell under ice growth conditions. It controls 

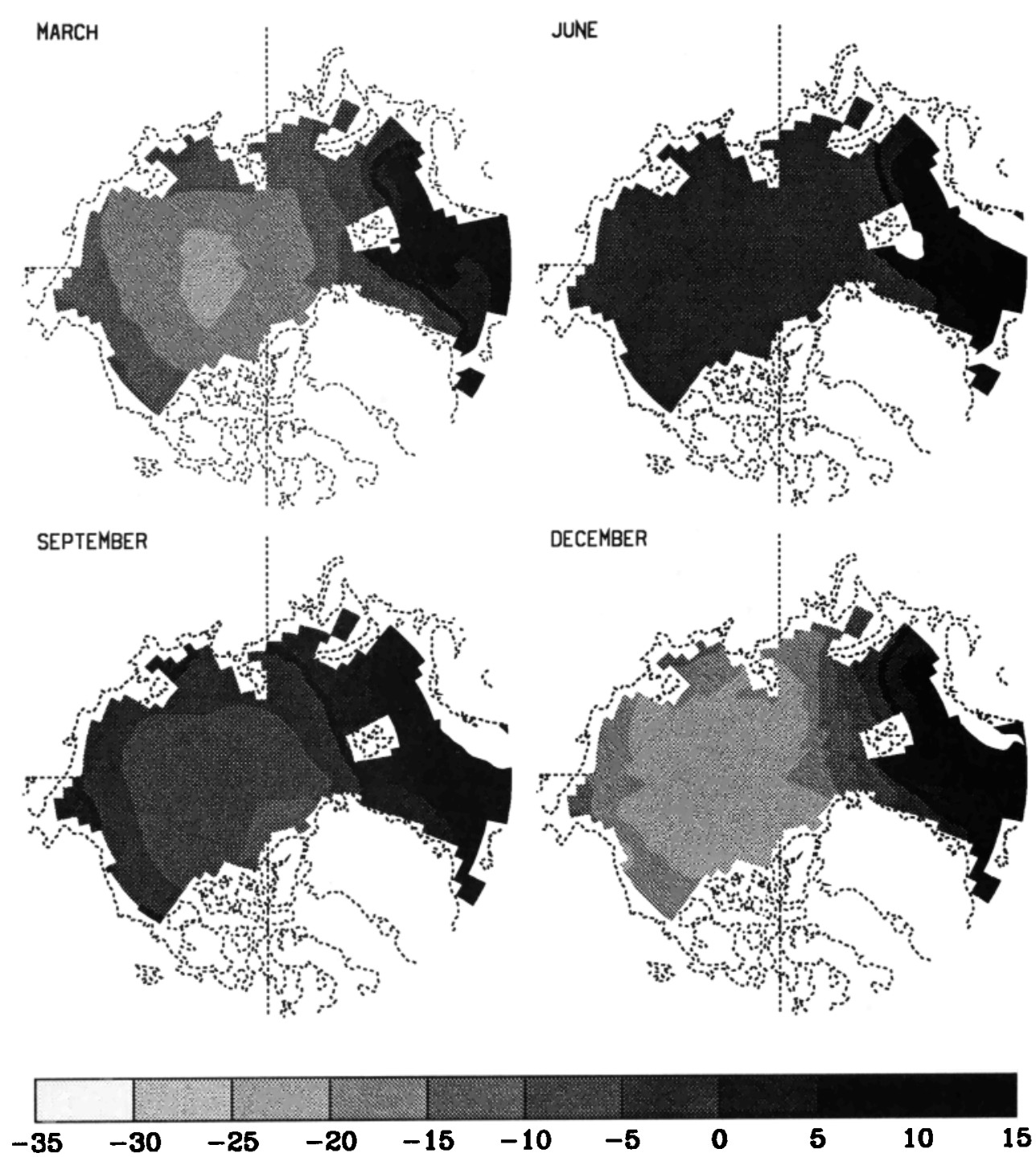

Fig. 6. Seasonally varying ice or ocean surface temperatures (in degrees Celsius) from the control simulation. Where ice exists the temperature given is that of the surface of the ice; where there is no ice, the temperature shown is that of the ocean surface. The heavy black line indicates the $0^{\circ}$ contour. The simulation produces a uniform temperature in the central Arctic in June during the surface melt period. The surface temperature is several degrees too high in the Norwegian Current.

the rate at which leads close or freeze over. The introduction of $C_{\text {frez }}$ is justified, as (5) is not based on rigorous physical principles, but rather on intuitive reasoning for the behavior of ice during growth. Essentially, $C_{\text {frez }}$ controls the rate at which open water is converted to ice-covered ocean. The control value is 1 . It is shown below that $C_{\text {frez }}$ is a key parameter that readily controls the ice thickness. Note that according to (5), there is a corresponding (but inverse)

TABLE 2. Numerical Conditions of Theme A

\begin{tabular}{llcc}
\hline $\begin{array}{c}\text { Experiment } \\
\text { Label }\end{array}$ & \multicolumn{1}{c}{ Experiment Description } & Experiment Value & $\begin{array}{c}\text { Control } \\
\text { Value }\end{array}$ \\
\hline A1 & Time step $\delta t$ & 2 hours & 12 hours \\
A2 & Time step $\delta t$ & 1 day & 12 hours \\
A3 & Total integration time & 100 years & 10 years \\
A4 & Initial ice compactness & $100 \%$ & $0 \%$ \\
A5 & Initial ice thickness & $10 \mathrm{~m}$ & 0 m \\
A6 & Initial ice velocity & $0.50 \mathrm{~m} \mathrm{~s}^{-1}$ & $0 \mathrm{~m} \mathrm{~s}^{-1}$ \\
A7 & Initial mixed layer temperature & $+5.0^{\circ} \mathrm{C}$ & $-1.8^{\circ} \mathrm{C}$ \\
A8 & Maximum number of interations & 50 & 100 \\
A9 & Machine accuracy constant & $10^{-20}$ & $10^{-100}$ \\
A10 & Boundary condition at North Pole & Free flow over pole & Stick at Pole \\
\hline & & &
\end{tabular}


TABLE 3. Parameter Values of Theme B

\begin{tabular}{|c|c|c|c|}
\hline $\begin{array}{l}\text { Experiment } \\
\text { Label }\end{array}$ & Experiment Description & $\begin{array}{l}\text { Experiment } \\
\text { Value }\end{array}$ & Control Value \\
\hline B1 & Ice strength $P^{*}$ & $1 \times 10^{3} \mathrm{~N} \mathrm{~m}^{-2}$ & $10 \times 10^{3} \mathrm{~N} \mathrm{~m}^{-2}$ \\
\hline B2 & Ice strength $P^{*}$ & $30 \times 10^{3} \mathrm{~N} \mathrm{~m}^{-2}$ & $10 \times 10^{3} \mathrm{~N} \mathrm{~m}^{-2}$ \\
\hline B3 & Ice strength decay constant $C^{*}$ & 5 & 10 \\
\hline B4 & Ice strength decay constant $C^{*}$ & 20 & 10 \\
\hline B5 & Yield curve eccentricity $e$ & 1 & 2 \\
\hline B6 & Yield curve eccentricity $e$ & 4 & 2 \\
\hline B7 & Coefficient of freezing $C_{\text {frez }}$ & $1 / 2$ & 1 \\
\hline B8 & Coefficient of freezing $C_{\text {frez }}$ & 2 & 1 \\
\hline B9 & Coefficient of melting $C_{\text {melt }}$ & $1 / 2$ & 1 \\
\hline B10 & Coefficient of melting $C_{\text {melt }}$ & 2 & 1 \\
\hline B11 & Coefficient of diffusion for ice thickness and compactness $A^{s}$ & $1 \times 10^{3} \mathrm{~m}^{2} \mathrm{~s}^{-1}$ & $2 \times 10 \mathrm{~m}^{2} \mathrm{~s}^{-1}$ \\
\hline B12 & Coefficient of diffusion for ice thickness and compactness $A^{s}$ & $20 \times 10^{3} \mathrm{~m}^{2} \mathrm{~s}^{-1}$ & $2 \times 10^{3} \mathrm{~m}^{2} \mathrm{~s}^{-1}$ \\
\hline B13 & Coefficient of diffusion for ice momentum $A^{m}$ & $0.2 \times 10^{3} \mathrm{~m}^{2} \mathrm{~s}^{-1}$ & $2 \times 10 \mathrm{~m}^{2} \mathrm{~s}^{-1}$ \\
\hline B14 & Coefficient of diffusion for ice momentum $A^{m}$ & $20 \times 10^{3} \mathrm{~m}^{2} \mathrm{~s}^{-1}$ & $2 \times 10 \mathrm{~m}^{2} \mathrm{~s}^{-1}$ \\
\hline B15 & Thermal conductivity of ice $\kappa_{\text {Ice }}$ & $0.1 \mathrm{~W} \mathrm{~m}^{-1} \mathrm{~K}^{-1}$ & $2 \mathrm{~W} \mathrm{~m}^{-1} \mathrm{~K}^{-1}$ \\
\hline B16 & Thermal conductivity of ice $\kappa_{\text {ice }}$ & $10 \mathrm{~W} \mathrm{~m}^{-1} \mathrm{~K}^{-1}$ & \\
\hline B17 & Ice surface albedo $\alpha_{1 c e}$ & 0.10 & 0.40 \\
\hline B18 & Ice surface albedo $\alpha_{\text {ice }}$ & 0.90 & 0.40 \\
\hline B19 & $\begin{array}{l}\text { Ice surface albedo } \alpha_{\text {ice }} \text { dependent on atmospheric surface } \\
\text { temperature }\end{array}$ & (8) & 0.40 \\
\hline B20 & Ocean surface albedo $\alpha_{1 c e}$ & 0.05 & 0.17 \\
\hline B21 & Ocean surface albedo $\alpha_{\text {ocn }}$ & 0.50 & 0.17 \\
\hline B22 & Atmospheric drag coefficient $C_{\text {gir }}$ & $0.12 \times 10^{-3}$ & $1.2 \times 10^{-3}$ \\
\hline B23 & Atmospheric drag coefficient $C_{\text {air }}$ & 12. $\times 10^{-3}$ & $1.2 \times 10^{-3}$ \\
\hline $\mathbf{B 2 4}$ & $\begin{array}{l}\text { Atmospheric drag coefficient } C_{\text {air }} \text { dependent on ice } \\
\text { compactness } q\end{array}$ & (9) & $1.2 \times 10^{-3}$ \\
\hline B25 & Oceanic drag coefficient $C_{\mathrm{acn}}$ & $0.55 \times 10^{-3}$ & $5.5 \times 10^{-3}$ \\
\hline B26 & Oceanic drag coefficient $C_{o c n}$ & $55 \times 10^{-3}$ & $5.5 \times 10^{-3}$ \\
\hline $\mathbf{B 2 7}$ & Coefficient for sensible and latent heat transfer $C_{\text {sens }}$ and $C_{\text {lat }}$ & $0.15 \times 10^{-3}$ & $1.5 \times 10^{-3}$ \\
\hline B28 & Coefficient for sensible and latent heat transfer $C_{\text {sens }}$ and $C_{\text {lat }}$ & $1.5 \times 10^{-3}$ & $1.5 \times 10^{-3}$ \\
\hline B29 & Shortwave cloud fraction $C_{f}$ & 0.55 & 0.85 \\
\hline B30 & Shortwave cloud fraction $C_{f}$ & 1.00 & 0.85 \\
\hline B31 & Monthly varying shortwave cloud fraction $C_{f}$ & Table 6 & 0.85 \\
\hline B32 & Monthly varying longwave and shortwave cloud fraction $C_{f}$ & Table 6 & 0.85 \\
\hline B33 & $\begin{array}{l}\text { Monthly varying longwave and shortwave cloud fraction } C_{f} \\
\text { decreased uniformly by } 0.20\end{array}$ & Table 6 & 8.85 \\
\hline B34 & $\begin{array}{l}\text { Monthly varying longwave and shortwave cloud fraction } C_{f} \\
\text { increased uniformly by } 0.20\end{array}$ & Table 6 & 0.85 \\
\hline B35 & Longwave emissivity of ice $\varepsilon_{i c e}$ and ocean $\varepsilon_{o c n}$ & 0.90 & 0.97 \\
\hline B36 & Maximum ice compactness $q_{\max }$ & 0.99 & 1.00 \\
\hline B37 & Maximum ice compactness $q_{\max }$ & 0.95 & 1.00 \\
\hline B38 & Mixed layer salinity $S_{\text {ocn }}$ & 30 psu & Spatially varying \\
\hline B39 & Mixed layer salinity $S_{\text {ocn }}$ & 0 psu & Spatially varying \\
\hline B40 & Mixed layer depth $h_{\text {ocn }}$ & $3 \mathrm{~m}$ & $30 \mathrm{~m}$ \\
\hline B41 & Mixed layer depth $h_{\text {ocn }}$ & $300 \mathrm{~m}$ & $30 \mathrm{~m}$ \\
\hline B42 & Mixed layer depth $h_{o c n}$ & Spatially varying & $30 \mathrm{~m}$ \\
\hline B43 & Deep ocean heat flux $Q_{o c n}$ & $0 \mathrm{~W} \mathrm{~m}^{-2}$ & Spatially varying \\
\hline B44 & Deep ocean heat flux $Q_{\text {ocn }}$ & $2 \mathrm{~W} \mathrm{~m}^{-2}$ & Spatially varying \\
\hline B45 & Deep ocean that flux $Q_{\text {ocn }}$ & $10 \mathrm{~W} \mathrm{~m}^{-2}$ & Spatially varying \\
\hline
\end{tabular}

sensitivity to $h_{0}$, which is also a very arbitrary parameter in this formulation. It is worth noting that (5) uses the ice growth rate $F_{h}$ averaged over a grid cell, which includes contributions from thick and thin ice. A more appropriate formulation would use the ice growth rate over open water only, as in Hibler [1979].

$B 7$ : Decreasing $C_{\text {frez }}$ to $1 / 2$ results in a decrease in the growth rate of compactness in a cell. This means that open water is slower to freeze over and, consequently, more heat is lost to the atmosphere and greater ice production is experienced. The average ice thickness increases by about 1 $\mathrm{m}$, while the seasonal cycles of areal coverage and compactness become less pronounced. This is a very realistic ice thickness simulation. The kinetic energy increases due to both the increase in ice thickness mentioned above, and also a more vigorous ice circulation.
B8: Increasing $C_{\text {frez }}$ to 2 results in behavior exactly the opposite to the above. Leads in the ice are now quicker to freeze over, and ice production is inhibited. Since there is much more thin ice produced, the seasonal cycles of areal coverage and compactness are accentuated because this ice has little thermal inertia.

Experiments B9 and B10: Coefficient of melting $C_{\text {melt }}$. The forcing term $F_{q}$ also describes the manner in which the ice compactness decreases in a given cell due to melting introduced by the thermodynamic forcing $F_{h}$. A coefficient of melting $C_{\text {melt }}$ is introduced into this relation between $F_{q}$ and $F_{h}$, as in (5). Essentially, $C_{\text {melt modifies the rate at }}$ which thick ice-covered ocean is converted to open water. It can be thought of as a parameter to control the rate at which leads open. The control value is 1 .

B9: Decreasing $C_{\text {melt }}$ to $1 / 2$ results in a slower conver- 
TABLE 4. Physical Processes of Theme C

\begin{tabular}{ll}
\hline $\begin{array}{c}\text { Experi- } \\
\text { ment } \\
\text { Label }\end{array}$ & \multicolumn{1}{c}{ Experiment Description } \\
\hline C1 & Downward shortwave radiation eliminated \\
C2 & Upward and downward longwave radiation eliminated \\
C3 & Sensible heat transfer eliminated \\
C4 & Latent heat transfer eliminated \\
C5 & Ice compactness equation eliminated \\
C6 & Atmospheric winds eliminated \\
C7 & Oceanic currents eliminated \\
C8 & Cavitating fluid rheology introduced \\
C9 & Ice rheology eliminated \\
C10 & Ocean surface tilt eliminated \\
C11 & f plane approximation \\
C12 & Coriolis force eliminated \\
C13 & Ice dynamics eliminated \\
C14 & Specific heat capacity introduced \\
C15 & Internal brine pockets introduced \\
C16 & Monthly snowfall introduced \\
C17 & Monthly snowfall (rate increased by factor of 5 ) \\
C18 & Atmospheric air temperature decreased uniformly by $5^{\circ} \mathrm{C}$ \\
C19 & Atmospheric air temperatures increased uniformly by $5^{\circ} \mathrm{C}$ \\
\hline
\end{tabular}

sion of ice to open water during the melting season; thus there is greater areal coverage and compactness during the melting season. The kinetic energy is largely unaffected. There is no change during the freezing season.

B10: Increasing $C_{\text {melt }}$ to 2 increases the rate of conversion of ice-covered ocean to open water. The result is less areal coverage and less compactness during the melting season. Again, there is little change in the kinetic energy of the ice. Interestingly enough, the seasonal cycle of the domain-averaged thickness indicates the ice to be thickest in August. Recall that the thickness is defined as the effective thickness in the time series; thus with this parameter setting, we see that most of the thin ice is melted during the course of the summer, leaving only very thick ice at the end of the summer. By contrast, in winter there is much more thin ice, in addition to the thick ice, and this gives rise to an effective winter thickness which is less than the summer thickness.

Experiments B17, B18, B19: Ice albedo $\alpha_{\text {ice }}$. In contrast to the ice conductivity, the ice albedo is an adjustable parameter. It is difficult to assign an appropriate value for

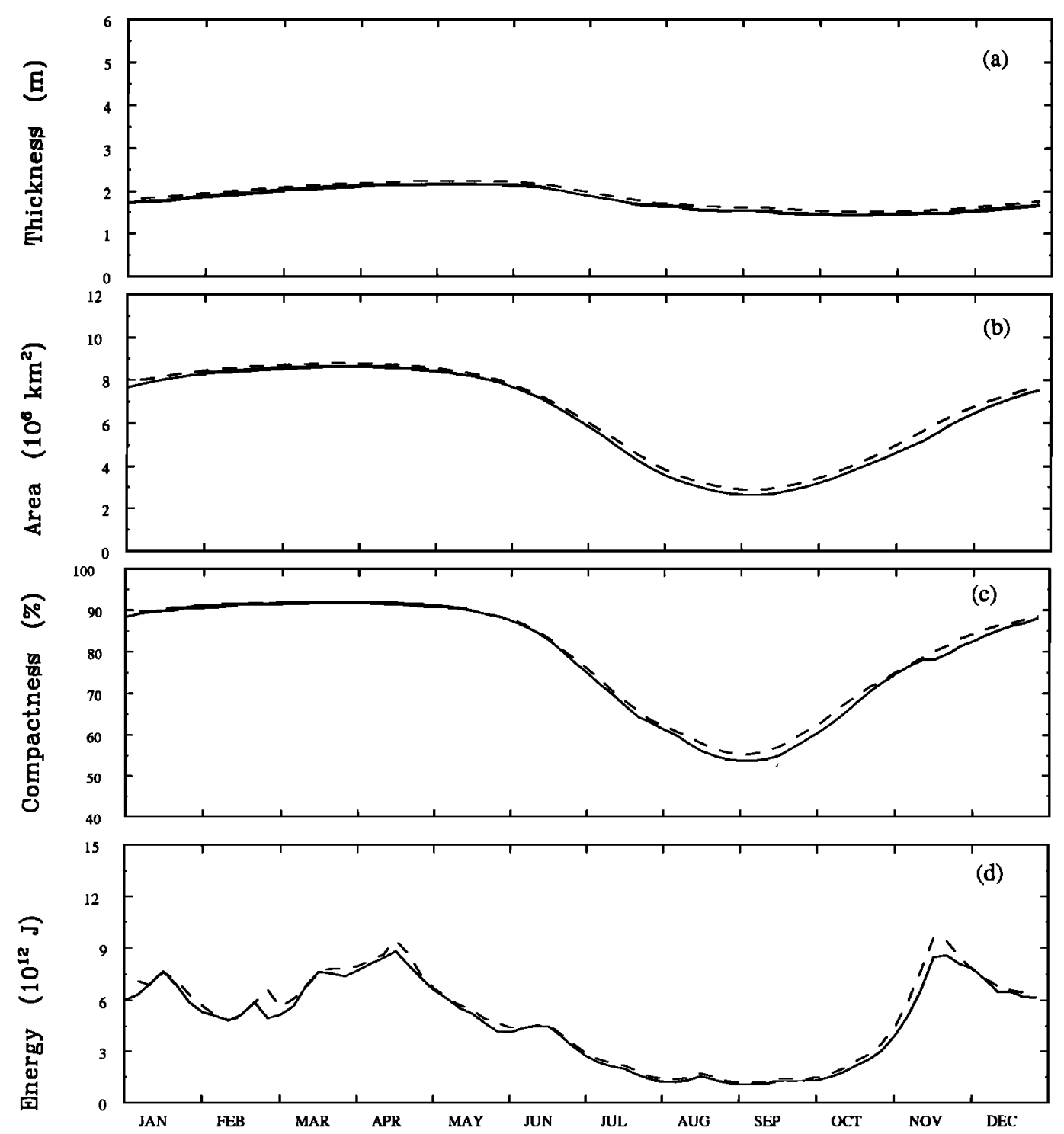

Fig. 7. Experiment A10 (boundary condition at pole). Time series of ice thickness, areal coverage, and kinetic energy over the equilibrium annual cycle. The dashed lines are the results from the control run. 

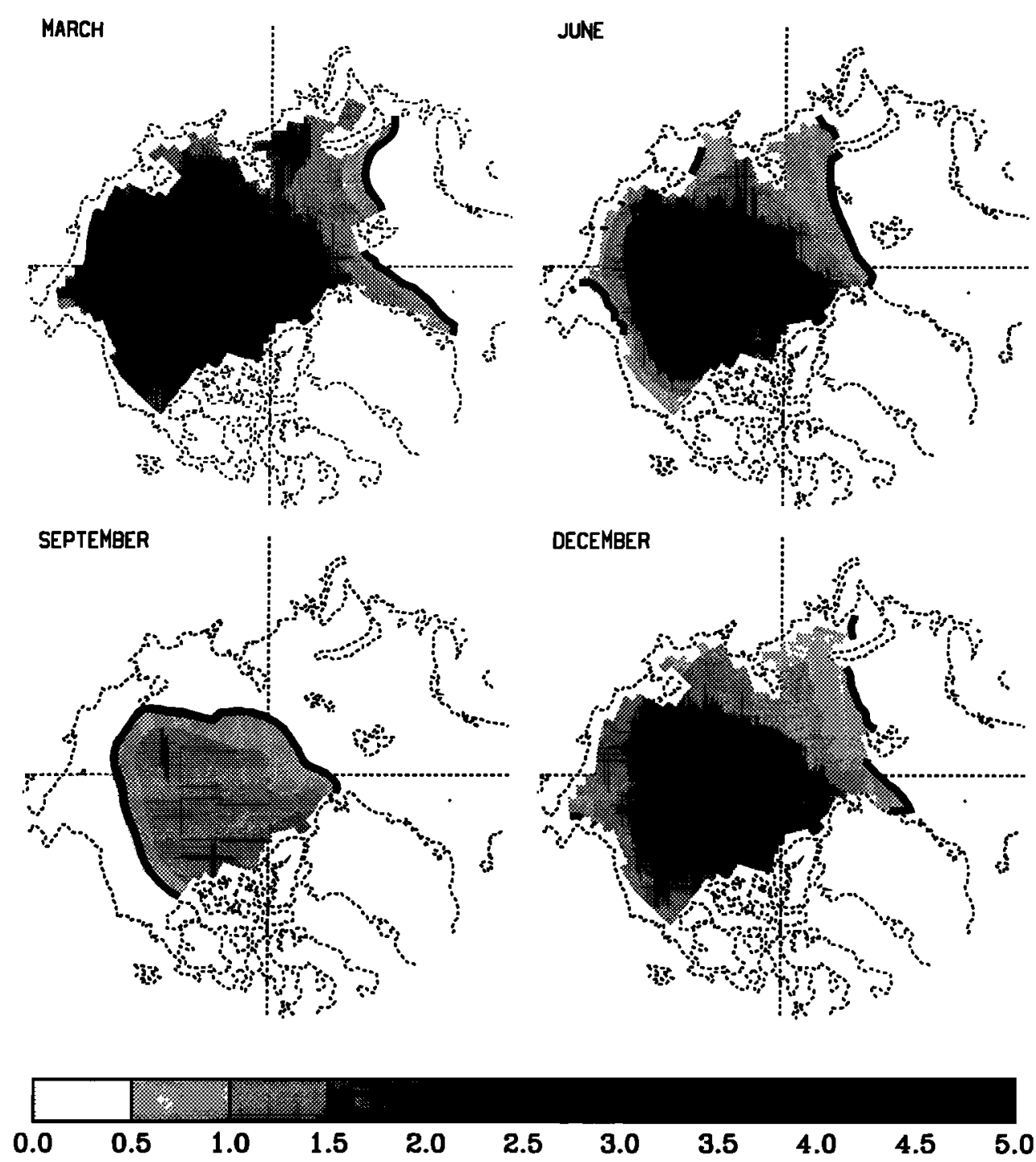

Fig. 8. Experiment A10 (boundary condition at pole). Seasonally varying ice thickness fields (in units of meters) from the simulation. The heavy black line indicates the $0.5-\mathrm{m}$ thickness contour.

$\alpha_{\text {ice }}$ because the surface reflective properties are highly variable. For instance, the surface may be covered by new snow, old snow, wet snow, ice, or melt ponds, thus giving rise to a large range of surface albedos. It is estimated that between 20 and $40 \%$ of the surface area is covered by low albedo melt ponds during the critical months of July and August. As with the preceding experiments, the idea here is to vary $\alpha_{\text {ice }}$ through extreme variations in order to observe the model's response. This also serves the purpose of assessing the model's robustness with respect to albedo. The control value is 0.40 .

B17: Decreasing the ice albedo to 0.10 results in a decrease in all of the ice fields. The most noticeable impact is on the September ice thickness and compactness fields. The ice, however, does not completely disappear.

B18: Making the ice surface highly reflective, by increasing the ice albedo to 0.90 , results in an increase in the ice thickness field to an average of about $4 \mathrm{~m}$. There is a large decrease in the amplitude of the seasonal cycles of areal coverage and ice compactness. The greatest changes are evident during the melt season.
B19: A further experiment in which the surface albedo was made continuously dependent upon the air temperature was carried out. This is a modification of the surface albedo representation given by Ross and Walsh [1987]:

$$
\begin{array}{lcl}
\alpha_{\text {ice }}=0.60 & T_{\text {air }}<-5^{\circ} \mathrm{C} \\
\alpha_{\text {ice }}=0.40-0.04 T_{\text {air }} & -5^{\circ} \mathrm{C}<T_{\text {air }}<+5^{\circ} \mathrm{C} \\
\alpha_{\text {ice }}=0.20 & T_{\text {air }}>+5^{\circ} \mathrm{C}
\end{array}
$$

Such a representation captures the decrease in albedo which occurs when relatively warm air appears over the ice surface; similarly, an increase in albedo occurs in the presence of a relatively cold air mass. Nevertheless, the results indicate that the model is not very sensitive to these details. This relative insensitivity is in agreement with similar results obtained by Fleming [1990] using a coupled ice-ocean model. As a possible explanation for this relative insensitivity, Fleming suggested that the ocean heat flux, ocean currents, and wind stress may be more dominant in controlling the ice 

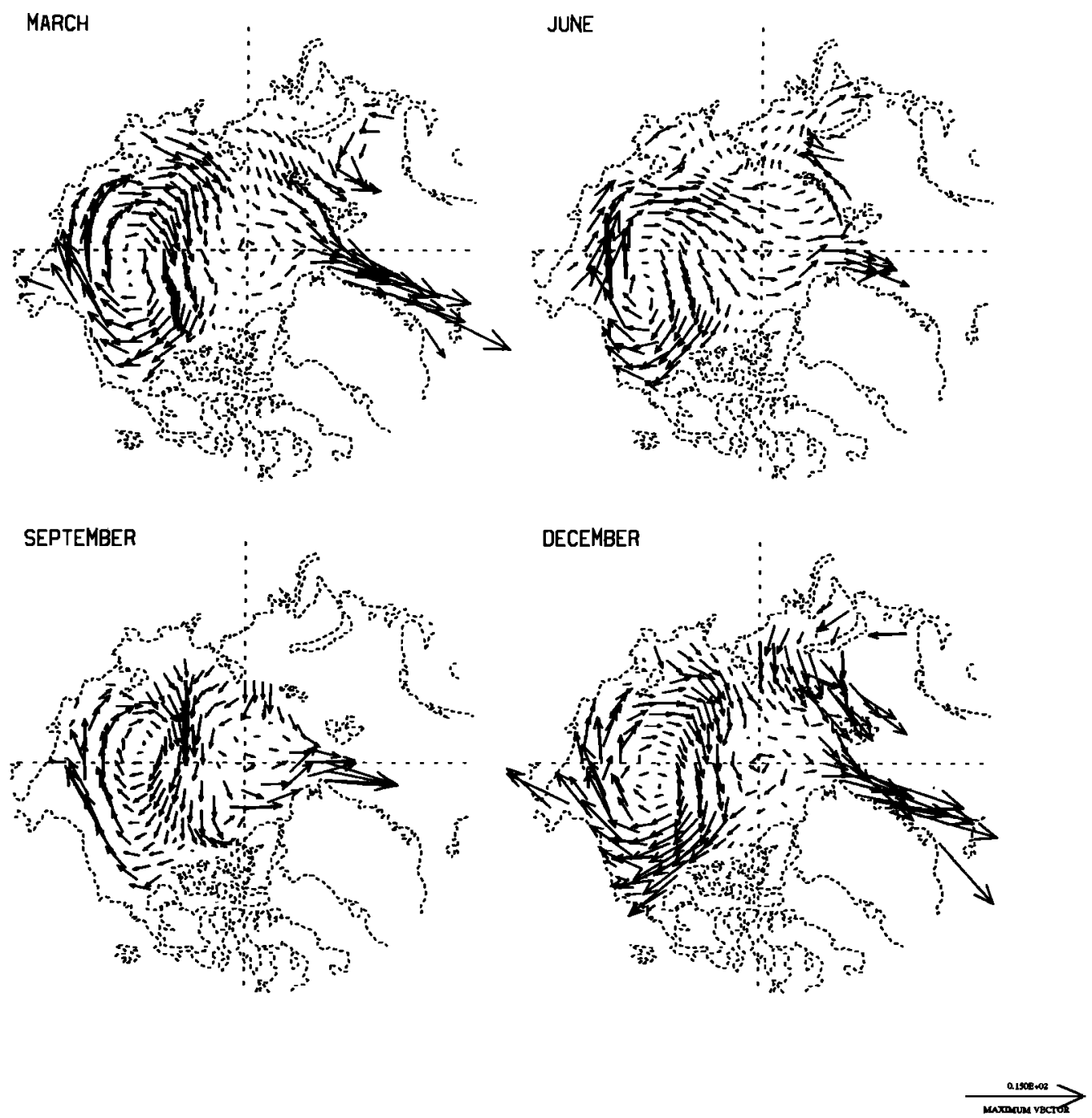

Fig. 9. Experiment A10 (boundary condition at pole). Seasonally varying ice velocity fields from the simulation. The largest vector represents an ice velocity of $15 \mathrm{~cm} / \mathrm{s}$.

edge than are the atmospheric heat flux changes to the ice resulting from albedo modifications.

Experiments B20 and B21: Ocean surface albedo $\alpha_{\text {ocn }}$. The ocean surface albedo has an impact both in the ice-free part of the model domain as well as in the leads between the ice floes. As with the ice albedo experiments, the model is expected to show the greatest sensitivity during the summer season. The control run value is 0.17 .

B20: Decreasing the ocean surface albedo to 0.05 gives a much more shortwave absorptive ocean surface. However, the impact on the ice simulation is minimal, with only a slight decrease in the ice characteristics. As expected, the greatest sensitivity is observed in September, i.e., at the end of the melt season.

B21: Increasing the ocean albedo to 0.50 simulates an unrealistically shortwave reflective ocean surface. Nevertheless, the changes to the control run simulation are moderate. There is an increase in the ice characteristics. Again, this change is most prominent at the end of the melting season.

Experiments B22, B23, and B24: Air drag coefficient $C_{\text {air }}$. The input of momentum to the ice from the atmosphere is based on a bulk aerodynamic formulation. In the control run the drag coefficient is taken as $1.2 \times 10^{-3}$. In this set of experiments, the drag parameter is changed to extreme values to observe the model's response. In reality, such extreme variations are likely to happen for a variety of reasons. First, the variations in atmospheric stability allow for enormous variations in the downward flux of momentum. Second, irregularities in the ice surface due to either ridging or leads can produce large fluctuations in the momentum flux via form drag.

B22: The reduction of $C_{\text {air }}$ by an order of magnitude to $0.12 \times 10^{-3}$ reduces the ice kinetic energy to about $30 \%$ of its control value. Interestingly enough, the modification of $C_{\text {air }}$ does not significantly affect the thermodynamic properties (i.e., the ice thickness, areal coverage, or compactness).

The kinetic energy of the ice pack integrated over the entire basin depends upon the momentum input from both the atmospheric winds and the oceanic currents. In comparing the seasonal fields of winds and currents, one can see that although these two fields have large-scale features in common (for instance, the Beaufort Gyre), over most grid points the vectors of wind and current have different directions. Consequently, the winds and currents may act in concert, or they may act in opposition when forcing ice 


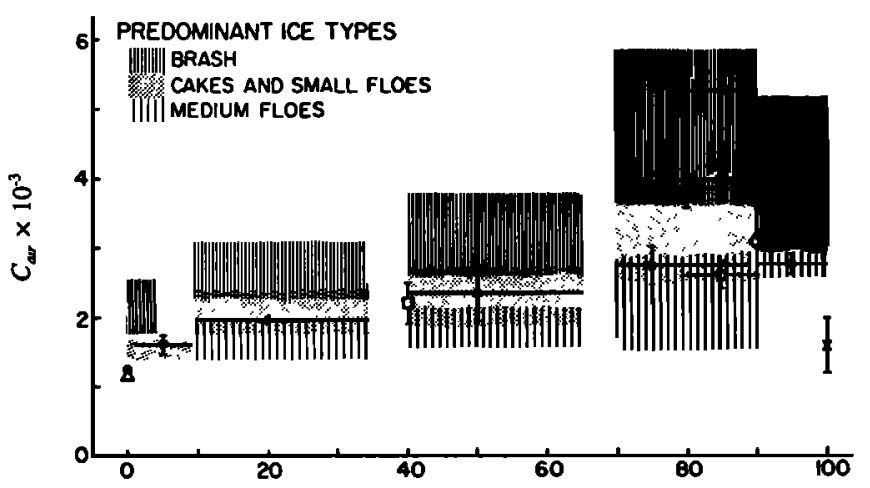

Ice Compactness $q \%$

Fig. 10. Atmospheric drag coefficient $C_{\text {air }}$ as a function of ice compactness $q$. The data are taken from several sources. The drag coefficient applies to several predominant ice types as indicated in the figure [from Anderson, 1987].

motion. A scale analysis of the atmospheric and ocean bulk drag formulations reveal that they are of the same order of magnitude. This fact coupled with the nonlinear nature of the drag laws plus the nonlinear nature of the ice rheology terms prohibit one from making simple predictions of the effect of altering the bulk drag coefficients.

B23: The increase of the drag coefficient by an order of magnitude to $12 \times 10^{-3}$ makes the ice pack extremely energetic and noisy, with November peak average kinetic energy 5 times the control value. At the same time, increasing $C_{\text {air }}$ also somewhat increases the ice thickness due to the increased percentage of open water during winter. Furthermore, the large ice velocities suggest the onset of numerical instability in the thickness and compactness fields.

B24: The variation of air drag coefficient with ice compactness $q$ has been investigated by Anderson [1987]. In Figure 10, one can see that the coefficient varies by a factor of 5 , depending on ice conditions. Note that it has a maximum value at a compactness of approximately $80 \%$. The dependence of drag coefficient on ice compactness is modeled from Figure 10 as

$$
\begin{array}{cc}
C_{\text {air }}=5 \times 10^{-3}\left(\frac{q}{0.8}\right) & q \leq 0.8 \\
C_{\text {air }}=5 \times 10^{-3}\left(\frac{1-q}{0.2}\right) & q>0.8
\end{array}
$$

Utilizing this dependency of drag coefficient on compactness, the major impact is to create a significant increase in the ice kinetic energy at the onset of winter, i.e., November (see Figure 11). Presumably, later in winter, the ice compactness is too high to allow efficient transfer of momentum from the atmosphere. In direct contrast to the preceding experiment, the average ice thickness actually decreases slightly. Hence one cannot make the statement that increased ice motion gives rise to increased production of open water (leads) and hence to increased ice growth.

Experiments B29-B34: Cloud fraction $C_{f}$. The following set of experiments investigates the impact of the cloud fraction on the shortwave radiation and then on the shortwave and longwave radiations combined. The monthly varying incoming solar radiation $Q_{\text {short }}$ was calculated as in
Parkinson and Washington [1979] by applying the cloudiness factor of Laevastu [1960] to an empirical equation given by Zillman [1972] for global radiation under cloudless skies. The cloudiness correction factor is

$$
1-0.6 C_{f}^{3}
$$

where $C_{f}$ is the cloud fraction; in the control run, $C_{f}$ is set to 85\%. This is in agreement with the summer time cloud cover values provided by Huschke [1969].

B29: Decreasing the shortwave cloud fraction to $55 \%$ causes the ice to almost completely disappear in September, due to the increased flux of solar radiation present at the surface of the ice. There is a reduction in all of the ice characteristics. The largest changes occur during the melt season.

B30: Increasing the shortwave cloud fraction $C_{f}$ to $100 \%$ generates an increase in all the ice characteristics. Note that $100 \%$ cloud cover does not imply zero solar radiation flux at the ice surface [Laevastu, 1960]. Again, the greatest changes take place during the melt season. The ice compactness fields of the control run indicate too great a meltback in the ice edge in June and September in comparison with observations from satellite [Parkinson et al., 1987]. This experiment demonstrated the exact opposite, i.e., insufficient meltback during the summer months. Nevertheless, there is an improvement with respect to the control run simulation. Furthermore, this simulation produced a realistic increase of the average ice thickness to just over $3 \mathrm{~m}$ compared to $2 \mathrm{~m}$ for the control run. Also, the surface temperature fields in the GIN seas become much more realistic than in the control run. Consequently, tuning the shortwave cloud parameter to lie between $85 \%$ and $100 \%$ may produce an improved simulation.

B31: A monthly varying cloud fraction is simulated using data from Huschke [1969] and is reproduced in Table 5. These values are incorporated into the shortwave radiation calculations. Clearly, the cloud fractions during the 6 months in which sunlight is absent are irrelevant. As for the six sunlit months, the cloud fraction specified is always less than that of the control run. The result of the simulation is then simply to decrease the ice characteristics with respect to the control simulation.

B32: A more interesting experiment is to incorporate the monthly cloud fractions into the longwave calculations as well as the shortwave. This allows the clouds to contribute to both heating (increased downwelling longwave) and cooling (decreased downwelling shortwave) in the net energy budget. The cloud fraction has an impact on the longwave radiation throughout the seasonal cycle, whereas the shortwave radiation is active only during the sunlit months. The net longwave radiation $Q_{\text {long }}$ at the surface is the sum total of the downward longwave radiation from the atmosphere $Q_{\text {down }}$, and the upwelling longwave radiation at the surface. The monthly varying downward component $Q_{\text {down }}$ was specified as in Parkinson and Washington [1979] by using the Idso and Jackson [1969] formula for clear skies. The upwelling radiation is expressed linearly in terms of the surface temperature using a polynomial expansion [Parkinson and Washington, 1979]. The effect of clouds on downward longwave radiation is parameterized using Marshunova [1966]:

$$
\left(1+0.16 C_{f}\right) \times Q_{\text {down }}
$$



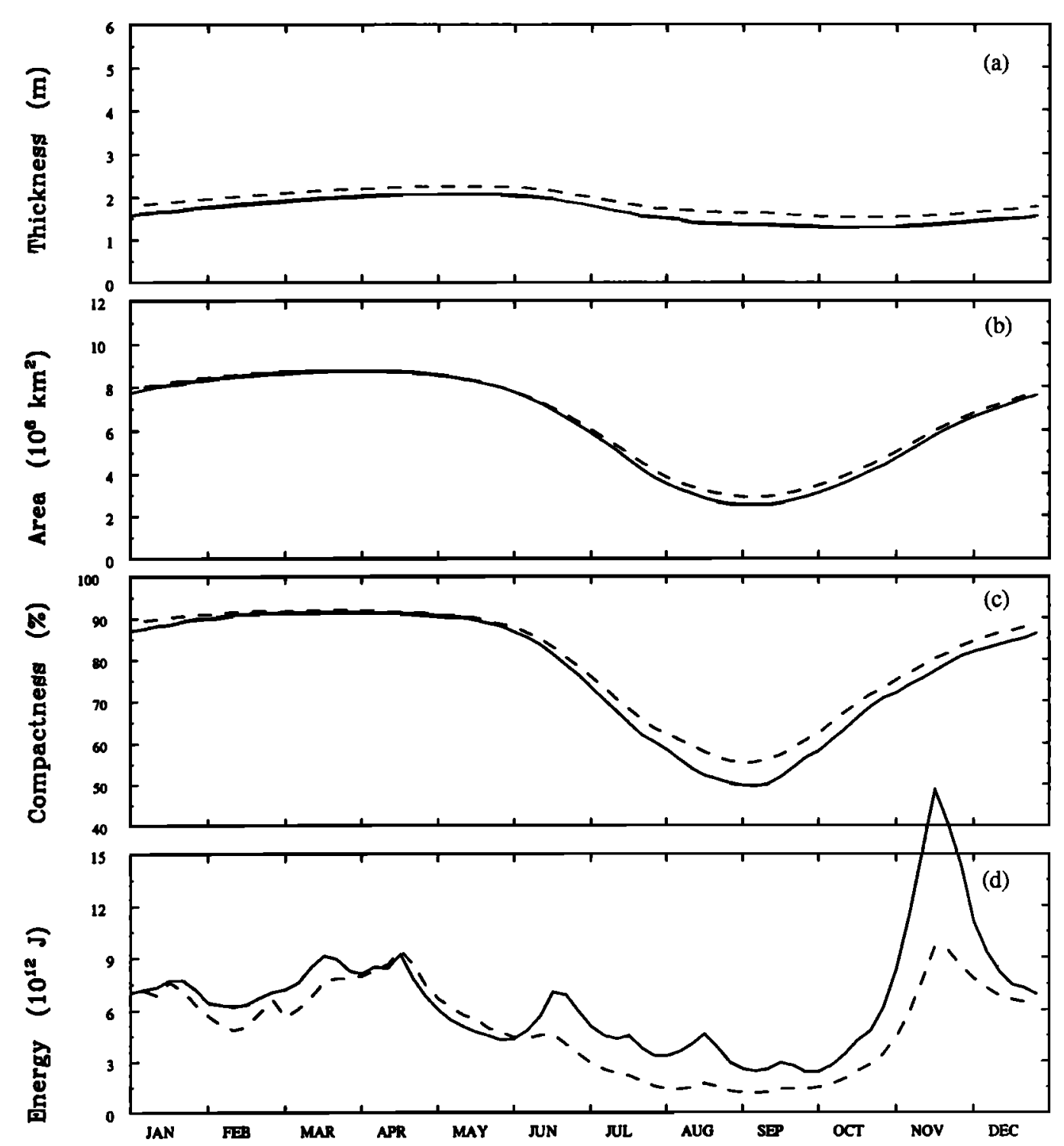

Fig. 11. Experiment B24 (air drag coefficient). Time series of ice thickness, areal coverage, compactuess, and kinetic energy over the equilibrium annual cycle. The dashed lines are the results from the control run.

Evidently, the impact of this modification, through increased heating, is to produce a decrease in the ice characteristics beyond that of the control run. In fact, the Arctic becomes ice free in September (see Figure 12).

Shine and Crane [1984] studied the sensitivity of a onedimensional thermodynamic sea ice model to changes in cloudiness. They utilized the same monthly cloud fraction as in Table 5. Based on the variability of cloud data collected over the period 1955-1960 they stated that departures from the mean cloud amount can exceed $20 \%$ and are generally highest during winter in all parts of the Arctic. As seen in the following two experiments, this $20 \%$ uncertainty in cloud amount can lead to large changes in the ice simulation.

B33: Uniformly decreasing all the cloud fractions in Table 5 by $20 \%$ produces an even more drastic ice meltback. The Arctic now remains ice free for almost the entire 2 months of August and September. Thus less cloud cover means less ice cover in this model. Shine and Crane [1984] speculated that a grid point model, such as used here, would simulate an expanded ice pack under decreased mean cloud conditions. The opposite result of this speculation was found here.

B34: Uniformly increasing all the cloud fractions in Table 5 by $20 \%$ produces a simulation closer to the control

TABLE 5. Monthly Cloud Fractions

\begin{tabular}{lc}
\hline Month & Cloud Fractions \\
\hline Jan. & 0.50 \\
Feb. & 0.50 \\
March & 0.50 \\
April & 0.55 \\
May & 0.70 \\
June & 0.75 \\
July & 0.75 \\
Aug. & 0.80 \\
Sept. & 0.80 \\
Oct. & 0.70 \\
Nov. & 0.60 \\
Dec. & 0.50 \\
\hline
\end{tabular}



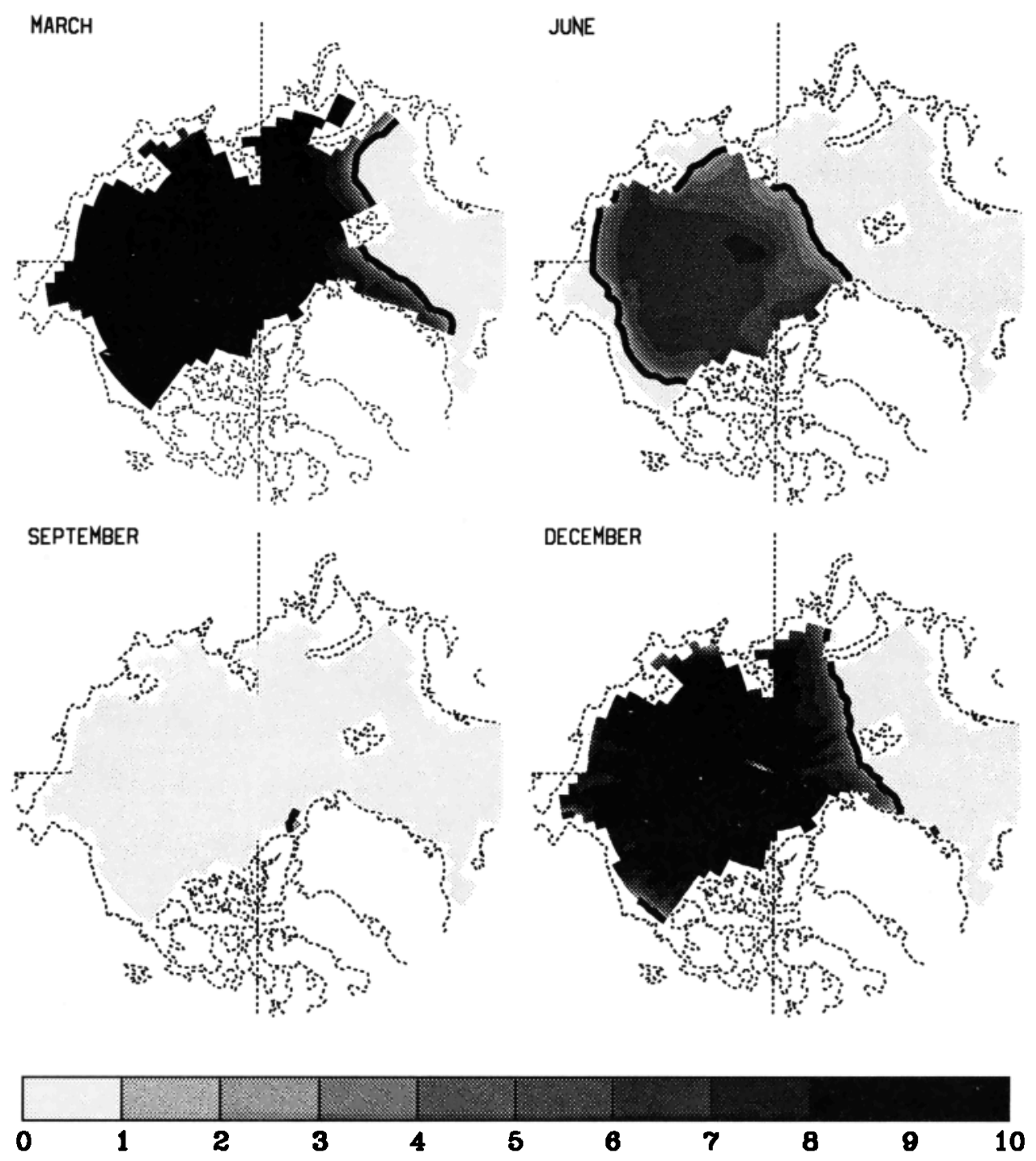

Fig. 12. Experiment B32 (shortwave and longwave cloud fraction). Seasonally varying ice compactness fields (in units of tenths) from the simulation. The heavy black line indicates the $1 / 10$ th compactness contour, considered as the ice edge.

simulation. The impact of increased cloud cover is to increase the ice characteristics. Shine and Crane [1984] also speculated that a grid point model would simulate an increased amplitude in the seasonal cycle of the areal extent under increased cloud conditions. However, because of the dominance of the ocean heat flux in the GIN seas, the wintertime ice edge extent is relatively insensitive to cloud cover there. Thus wintertime ice edge extent is relatively insensitive to small variations in cloud cover. The summertime ice extent, however, is more sensitive to cloud cover.

Shine and Crane made the following conclusions based on their investigation using a one-dimensional thermodynamic sea ice model. "A cloud decrease leads to an increase of the ice thickness, while a cloud increase leads to a thinning of the ice. The cooling of the surface with decreasing cloud cover implies that on an annual basis, clouds act to warm the surface and reduce the ice thickness. This is not surprising given the absence of the sun during the winter." Furthermore, concerning the relative importance of shortwave to longwave fluxes, they added that "changes in the shortwave flux due to variations in cloud amount never dominate the longwave fluxes to any great extent while ice is present."

Based on the results of the three-dimensional dynamic thermodynamic model used here, we would tend to draw the exact opposite conclusions. Shine and Crane [1984] found that with respect to changes in cloud cover, changes in the longwave flux dominate the radiation flux; however, we find that the shortwave flux causes the greatest change in the net radiation flux under changing cloud conditions. The parameterization of the effect of clouds on the shortwave (10) and the longwave radiation (11) used in this study differ slightly from the corresponding parameterizations used by Shine and Crane [1984]. Consequently, the difference noted here between our results and those of Shine and Crane may be as much dependent upon the longwave and shortwave cloud parameterizations as in the difference between a onedimensional and three-dimensional model.

To answer the question as to whether the net effect of clouds is to heat or to cool the Arctic surface, one requires further study into the sensitivity of this net cloud effect with 
respect to surface albedo, longwave flux parameterization, and shortwave parameterization. It should be noted that first-year and multiyear ice have different thermal properties with respect to melting and freezing, and albedo. These differences are expected to be an important factor in the response of sea ice to cloud forcing. Thus the distinction between these two classes of ice would have to be incorporated into the model before further progress can be made.

Experiments B36 and B37: Maximum ice compactness $q_{\max }$. The ice compactness equation (3) has the imposed condition that the ice compactness in a grid cell may not exceed some maximum value. In the control run this maximum value is taken as $100 \%$. In the central Arctic a certain percentage of open water is always observed in the ice pack even during winter. Such leads can be important for the heat budget, as the presence of a lead allows for as much as a 2 orders of magnitude increased heat loss over what would occur through an ice-covered surface.

B36: In the central Arctic, estimates of the fraction of open water have been placed at $1-2 \%$. This sea ice model is insensitive to the specification of such a fraction of open water. Setting $q_{\max }$ at $99 \%$ resulted in an almost identical simulation to that of the control run.

B37: Decreasing $q_{\max }$ to $95 \%$ and thus forcing each grid cell to have at least $5 \%$ open water at all times does generate a $20-\mathrm{cm}$ thicker average ice cover. This is because of the increased heat loss through the leads, which in turn results in greater ice production. At the same time, the amplitudes of the seasonal cycles of areal coverage and ice compactness are marginally decreased.

Experiments B43-B45: Ocean heat flux $Q_{\mathrm{ocn}}$. The diagnostic ocean heat flux used in the control run was obtained from output from a prognostic ocean general circulation model [Semtner, 1987]. The most prominent feature is that of a large upward heat flux during the winter months, just south of Spitsbergen. The values are of the order of $500 \mathrm{~W} / \mathrm{m}^{2}$, which for comparison, are far in excess of the solar radiation flux during summer. Such a large heat flux is dominant in melting the ice and, as it turns out, determines the position of the ice edge in the GIN seas [Hibler and Bryan, 1987]. The ocean heat flux $Q_{\text {ocn }}$ enters the model calculations through the thermodynamic forcing term $F_{h}$ in (4).

B43: Completely eliminating $Q_{\mathrm{ocn}}$, by setting it to zero, leads to a $25-\mathrm{cm}$ increase in the average annual ice thickness. There is a large increase in areal coverage as well as an increase in summertime compactness. The ice compactness fields indicate that the ice extent in March and December is far too great both in the Barents Sea and the GIN seas. The spatial fields of thickness and compactness resemble those of Parkinson and Washington [1979] in that there is a grossly exaggerated ice margin in the GIN seas. However, the surface temperature fields along the Norwegian Coast decrease and are in fact more realistic.

Semtner [1987] performed a sensitivity experiment with a coupled ice-ocean model in which he effectively replaced the prognostic ocean component by a simple mixed layer, which did not model either ocean currents or upward ocean heat flux. He stated that removing the prognostic ocean led to thicker and more compact ice. In the experiment performed here, in which only the upward ocean heat flux was eliminated, the ice also became thicker and more compact throughout the year. In particular, the $10 \%$ increase in compactness Semtner quoted for September is very similar to the increase in September seen in this experiment.

B44: Previous studies have set $Q_{\text {ocn }}$ to $2 \mathrm{~W} / \mathrm{m}^{2}$ everywhere [Maykut and Untersteiner, 1971; Parkinson and Washington, 1979]. Using such a value leads to an average ice thickness very similar to the control run. However, once again, the southward ice extent in the GIN seas in December and March is grossly exaggerated (see Figure 13).

B45: Increasing $Q_{\text {ocn }}$ to a constant value of $10 \mathrm{~W} / \mathrm{m}^{2}$ everywhere produced an unrealistic seasonal cycle of both ice areal extent and compactness. The ice extent is far too small in September and far too great in March. Thus a spatially and temporally varying field of $Q_{\text {ocn }}$ is crucial to a realistic simulation.

\subsection{Physical Processes (Theme C)}

Experiments C8 and C9: Ice rheology 1 . The internal ice force term I of the momentum equation (1) is the viscousplastic formulation of Hibler [1979] as applied to a spherical grid. This rheology is believed to be most appropriate to daily dynamic forcing, as opposed to the monthly forcing employed here. The reasoning is that daily forcing contains individual synoptic weather events which may produce large shearing forces in the ice pack. The viscous-plastic rheology models the shearing stresses experienced by ice under such conditions.

C8: Another formulation of the ice internal force $I$ is to use a cavitating fluid formulation in which the ice is resistive to compressive stresses but not to shear stresses [Flato and Hibler, 1992]. This is accomplished in practice by setting $e$ to a very large number. Such a rheology formulation is believed to be more appropriate to monthly wind forcing which does not contain synoptic-scale events which normally lead to large shear stresses. Eliminating the shear stresses results in a more energetic ice pack (30\%) between the months of December and May. Clearly, the shear stresses present in the viscous-plastic formulation only play a significant role during that part of the year during which the average compactness is very high (i.e., above 90\%). Interestingly enough, there is no accompanying change in the average ice thickness or areal coverage.

C9: Eliminating completely the ice internal force I gives a free drift simulation. The average ice thickness in the Beaufort Sea is just over $3 \mathrm{~m}$, although there is still some buildup of thick ice along the Canadian Archipelago and northern Greenland. The increased thickness of the ice gives the ice pack greater thermal inertia; thus there is a decrease in the amplitudes of the seasonal cycle of average ice areal extent and compactness. With this elimination of internal stresses between ice floes, the average kinetic energy increases between the months of November and May. In particular, the ice velocity field in December highlights this increased kinetic energy by giving a much stronger Transpolar Drift Stream, as well as a strong anticyclonic flow in the center of the Canadian Basin.

Experiments C14 and C15: Ice heat storage. Sea ice has two mechanisms for the storage of heat. First, the ice has a specific heat capacity. This is a thermal inertia that requires the input of energy to raise the temperature of the ice; likewise energy is released when the ice is cooled. Second, the ice has internal brine pockets which store energy in the form of latent heat by absorbing solar radiation. These brine 

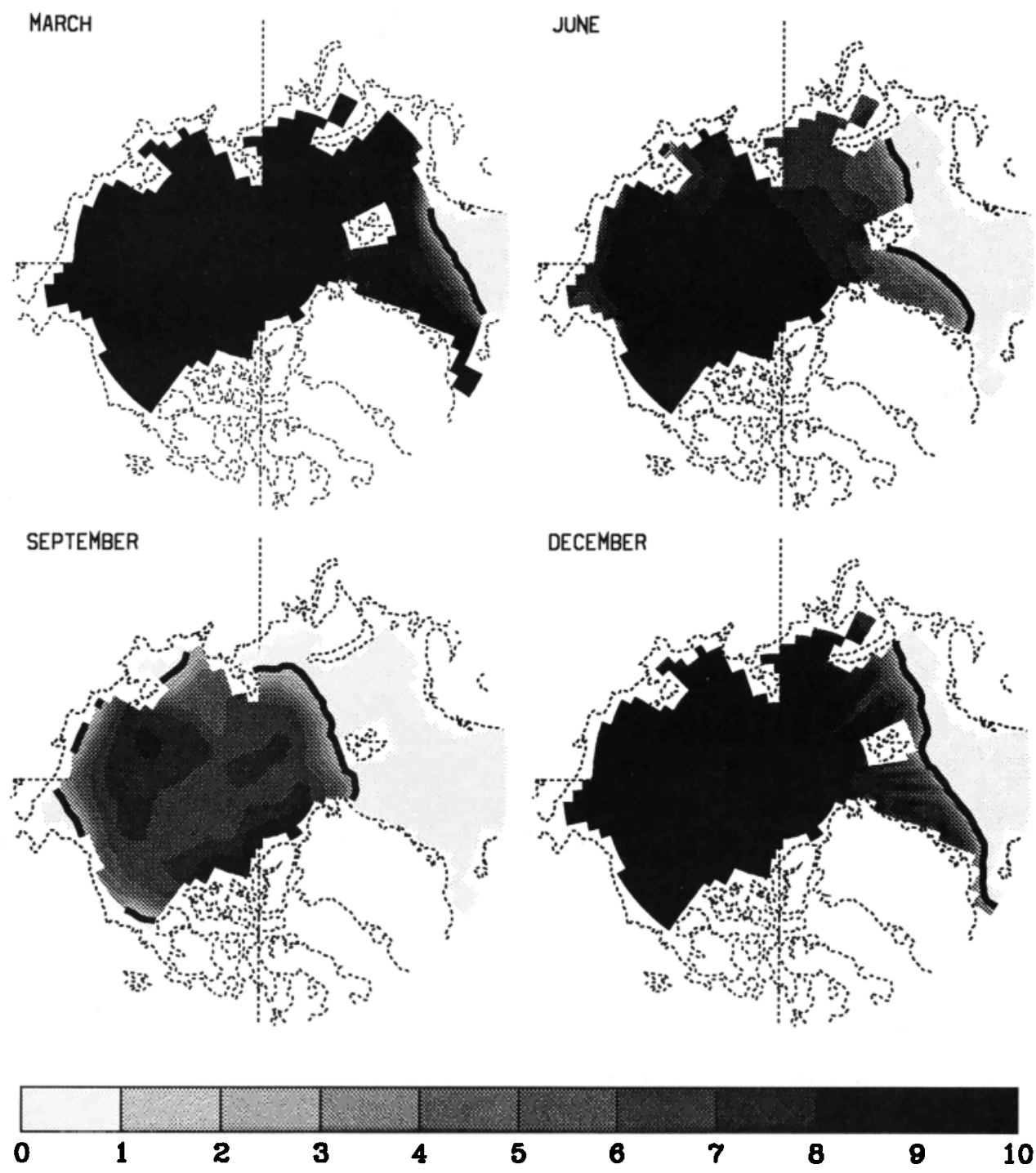

Fig. 13. Experiment B44 (ocean heat flux). Seasonally varying ice compactness fields (in units of tenths) from the simulation. The heavy black line indicates the $1 / 10$ th compactness contour, considered as the ice edge.

pockets release this stored heat in the fall during refreezing. Neither of these heat storage mechanisms is modeled in the control run.

C14: Consider an ice floe of effective thickness $h / q$, surface temperature $T_{\text {surf }}$, bottom temperature $T_{\text {ocn }}$, density $\rho_{\text {ice, }}$ and heat capacity $c_{p}$,ice. The amount of heat that must be extracted to lower the surface temperature of the ice to $T_{\text {surf }}^{\prime}$ is

$$
\frac{1}{2} \rho_{\text {ice }} \frac{h}{q} c_{p, \text { ice }}\left(T_{\text {surf }}^{\prime}-T_{\text {surf }}\right) .
$$

This amount of heat is represented by the shaded area in Figure 14. This additional heat term was added to the thermodynamic heat budget for the model.

Assigning the ice a heat capacity equal to $2090 \mathrm{~J} / \mathrm{kg} \mathrm{K}$ serves to shift the phase of the seasonal cycle of ice compactness. The ice reaches minimum compactness about 2 weeks later than in the control run. This is a result of the delay introduced to the heating and cooling process by the heat capacity. There are no other noticeable changes.
C15: The modeling of heat storage by internal brine pockets is carried out as in Semtner [1976]. With the appearance of the sun in spring, heat is accumulated in the brine pockets throughout the summer by absorbing $17 \%$ of

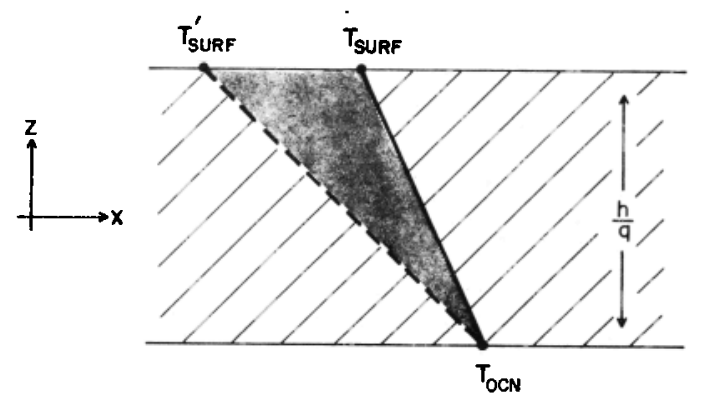

Fig. 14. Specific heat change in sea ice associated with a change of surface temperature from $T_{\text {surf }}$ to $T_{\text {surf. }}^{\prime}$. The ice is shown in vertical profile and is of effective thickness $h / q$, with bottom temperature $T_{\text {ocn }}$. The specific heat is proportional to the stippled area. 


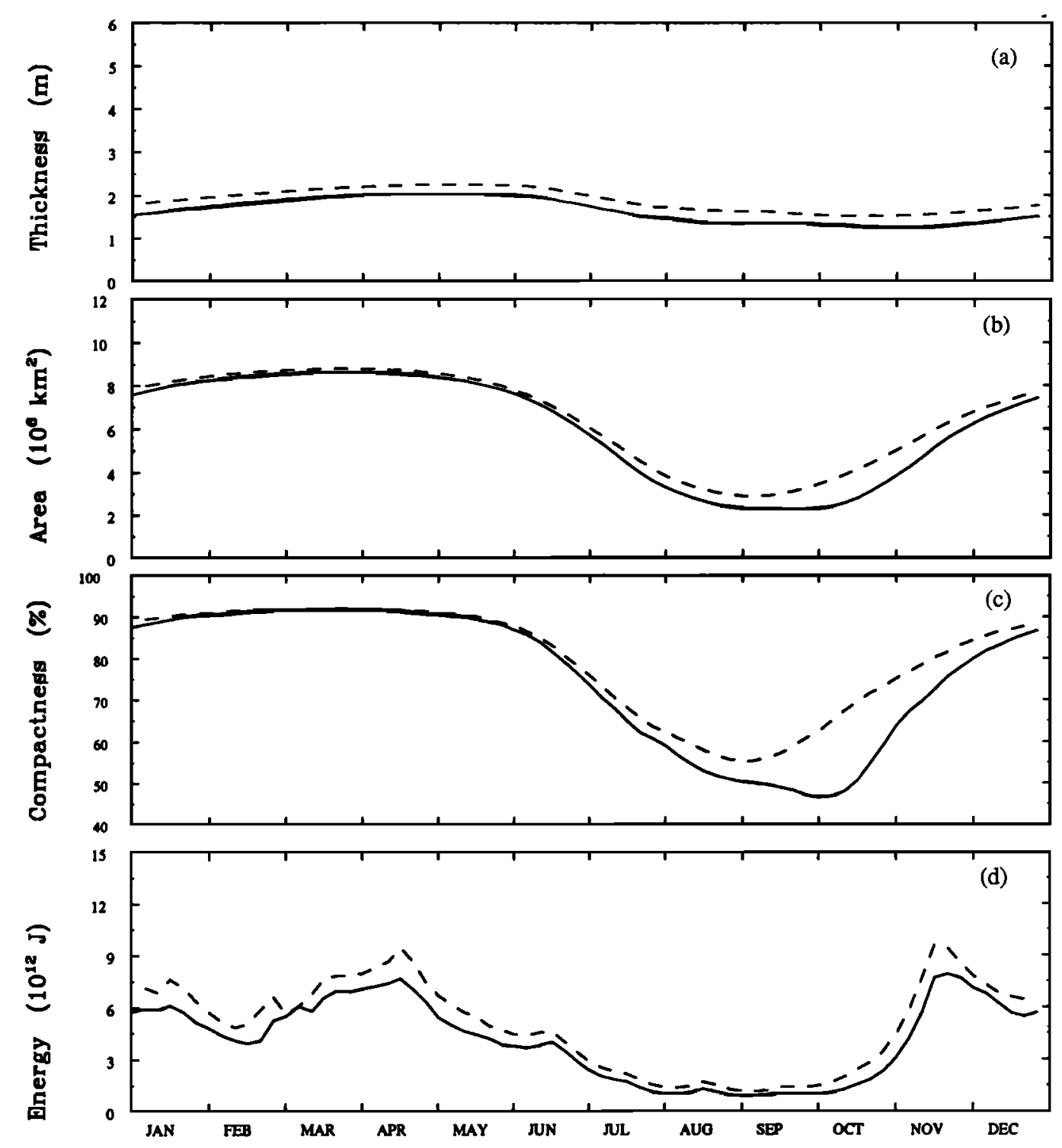

Fig. 15. Experiment C15 (brine pockets). Time series of ice thickness, areal coverage, compactness, and kinetic energy over the equilibrium annual cycle. The dashed lines are the results from the control run.

the incident solar radiation [Maykut and Untersteiner, 1971]. The heat accumulation is arbitrarily limited to $30 \%$ of the heat required to melt the ice. In fall, the heat reservoir is fully exhausted prior to the recommencement of ice growth.

Introducing brine pockets into the ice reduces the average ice thickness by about $20 \mathrm{~cm}$ (Figure 15). There are comparable decreases in the ice areal coverage, compactness, and kinetic energy. Particularly interesting is the change in the seasonal cycle of compactness. The inclusion of brine pockets delays the fall freeze-up by approximately 6 weeks (see Figure 15). The effects of the brine pockets is much greater than that of the ice specific heat (experiment C14).

Experiments $C 16$ and C17: Snow cover. The presence of a snow cover on the ice surface can alter the thermodynamic response of the ice. The snow does not affect the dynamics of the ice, as snow contributes little to the mass of an ice floe and has negligible strength. However, the presence of snow may lead to either a decreased or an increased ice melt rate. The higher albedo of the snow causes it to reflect more solar radiation than snow-free ice; this leads to a decreased ice melt rate. In contrast, snow has a smaller thermal conductivity than ice, thus leading to greater insulation of the atmosphere from the ocean than for snow-free ice. This means a decrease in both the ice melt and growth rates. The monthly snow rates for the Arctic are taken from Maykut and Untersteiner [1971] and are given in Table 6. The total annual snowfall is $40 \mathrm{~cm} / \mathrm{yr}$, with the greatest snowfall occurring during the fall. The snow accumulates at the prescribed rate provided the surface temperature is not above the freezing point. The values of the snow physical parameters are conductivity of $0.3 \mathrm{~W} / \mathrm{m} \mathrm{K}$, albedo of 0.70 , density of $330 \mathrm{~kg} / \mathrm{m}^{3}$, and emissivity of 0.99 . In essence, the layer of snow and the layer of ice are treated as a single layer with an effective thermal conductivity. This effective conductivity is obtained by taking a weighted average of the ice and snow thicknesses [Hibler, 1980], viz.,

$$
k_{\text {eff }}=\frac{h_{\text {ice }} k_{\text {ice }}}{h_{\text {ice }}+\left(k_{\text {ice }} / k_{\text {snow }}\right) h_{\text {snow }}}
$$


TABLE 6. Monthly Snowfall Rates

\begin{tabular}{lc}
\hline Month & Rate, cm/month \\
\hline Jan. & 0.83 \\
Feb. & 0.83 \\
March & 0.83 \\
April & 0.83 \\
May & 0.50 \\
June & 0.0 \\
July & 0.0 \\
Aug. & 12.8 \\
Sept. & 12.8 \\
Oct. & 12.8 \\
Nov. & 0.83 \\
Dec. & 0.83 \\
\hline
\end{tabular}

where $h_{\text {ice }}$ and $h_{\text {snow }}$ are the ice and snow thickness, respectively, while $\kappa_{\text {ice }}$ and $\kappa_{\text {snow }}$ are the ice and snow thermal conductivities, respectively. This treatment means that it is unnecessary to solve for the interface temperature between the snow and the ice. It is reasonable to assume that there is no net divergence of heat flux at this ice-snow interface.

C16: The desire to include snow cover in the sea ice model was motivated by the interesting multiyear cycle of ice thickness reported by Semtner [1976] in his thermodynamic model (Figure 16). Semtner found a "natural oscillation" in the sea ice thickness with a period of 6 years, even though the same forcing was applied each year. He attributed this behavior to the differing conductivities of the snow and ice. He suggested that this may be an important feature leading to multiyear anomalies in the observed ice cover. Washington et al. [1976] extended the Semtner model to three dimensions and reported finding a similar multiyear cycle in the ice thickness. Parkinson and Kellogg [1979], using a three-dimensional dynamic thermodynamic model, did not find a multiyear cycle. In a one-dimensional thermodynamic sea ice model, Shine and Crane [1984] reported finding a multiyear cycle of ice thickness. However, they argued that these oscillations are unlikely to be real features of the ice behavior. Instead, they suggested that the oscillations may be due to the rigid specification of snowfall rates on particular dates, whereas in nature it is possible the periods of maximum snowfall are related to dates of freezeup. These rates are poorly known and probably undergo large spatial and interannual variations.

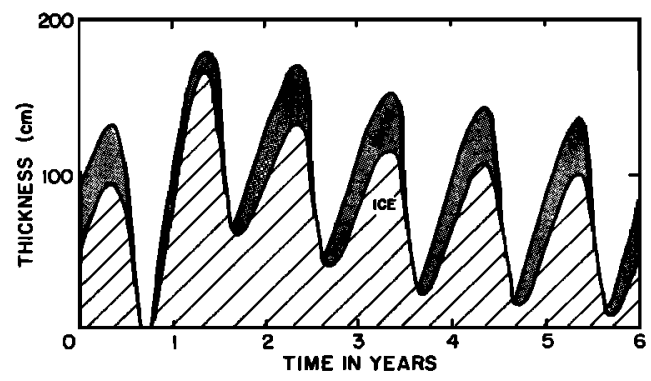

Fig. 16. Multiyear equilibrium cycle of ice thickness, as predicted by the thermodynamic model of Semtner [1976]. Washington et al. [1976] extended this model to three dimensions and again found such an interannual cycle. No such interannual cycles are found in the model investigated here. Note that in the figure the cycle period is 6 years.

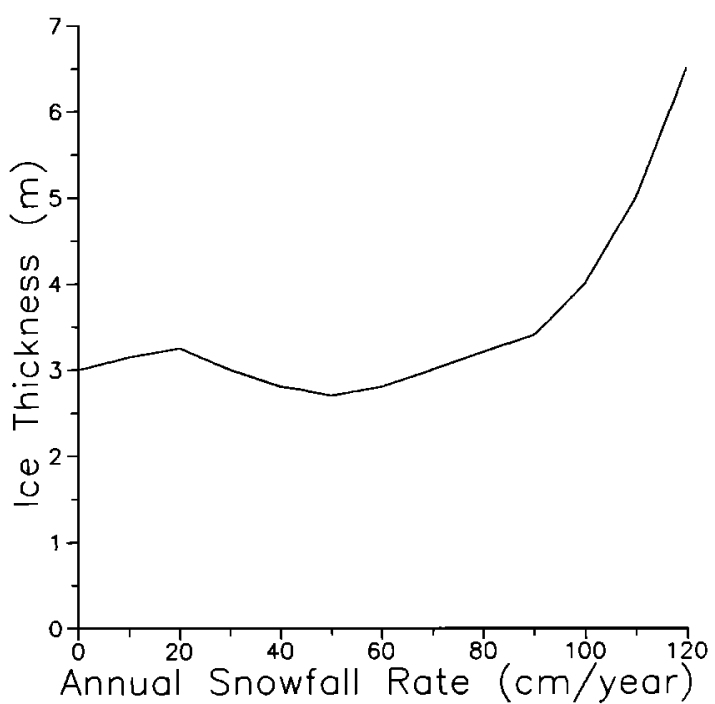

Fig. 17. Average equilibrium thickness of Arctic sea ice as a function of maximal annual snow depth from the thermodynamic model of Maykut and Untersteiner [1971]. Annual snow accumulations in excess of $120 \mathrm{~cm}$ result in incomplete melting of the snow cover, and the equilibrium sea ice thickness increases dramatically. No such increase is detected in the model investigated here.

The introduction of snow cover into this sea ice model gives a slightly thicker ice cover from June through December. There is also a noticeable increase in both areal coverage and compactness between June and October. The presence of the snow cover leads to colder ice surface temperature fields in March and December, with temperatures in the central Arctic being approximately $5^{\circ} \mathrm{C}$ colder than for the control run. In contrast to the findings of Semtner, of Washington et al., and of Shine and Crane, no such multiyear cycle was observed in this dynamic thermodynamic model. In a further experiment, dynamics were eliminated from the model, and still a multiyear cycle in ice thickness was not detected.

C17: This experiment was motivated by an experiment of Maykut and Untersteiner [1971] in which the snowfall rate was increased above the $40 \mathrm{~cm} / \mathrm{yr}$ rate specified in Table 6 . They found that for an annual snowfall rate in excess of about $120 \mathrm{~cm} / \mathrm{yr}$, the mean annual ice thickness increased without bound (Figure 17). Semtner [1976] was led to the same result using his simplified one-dimensional thermodynamic sea ice model.

In this model, increasing the annual snow rate by a factor of 5 (giving an annual total snowfall of $200 \mathrm{~cm} / \mathrm{yr}$ ) produces significant changes in the model response (see Figure 18). However, unlike in the Maykut and Untersteiner model, the sea ice thickness did not increase in an unbounded manner. The average ice thickness increases by about $0.5 \mathrm{~m}$, while the areal coverage and compactness are much greater in September compared to the control run cases. Again, a large areal extent of the central Arctic is about $5^{\circ} \mathrm{C}$ colder in the presence of this increased snow cover. The results indicate that the ice pack is not unstable with respect to a significant increase in precipitation. Such an increase in precipitation could occur under a climate change scenario.

These results indicate that a dynamic thermodynamic model is less sensitive to parameter changes than a simple 


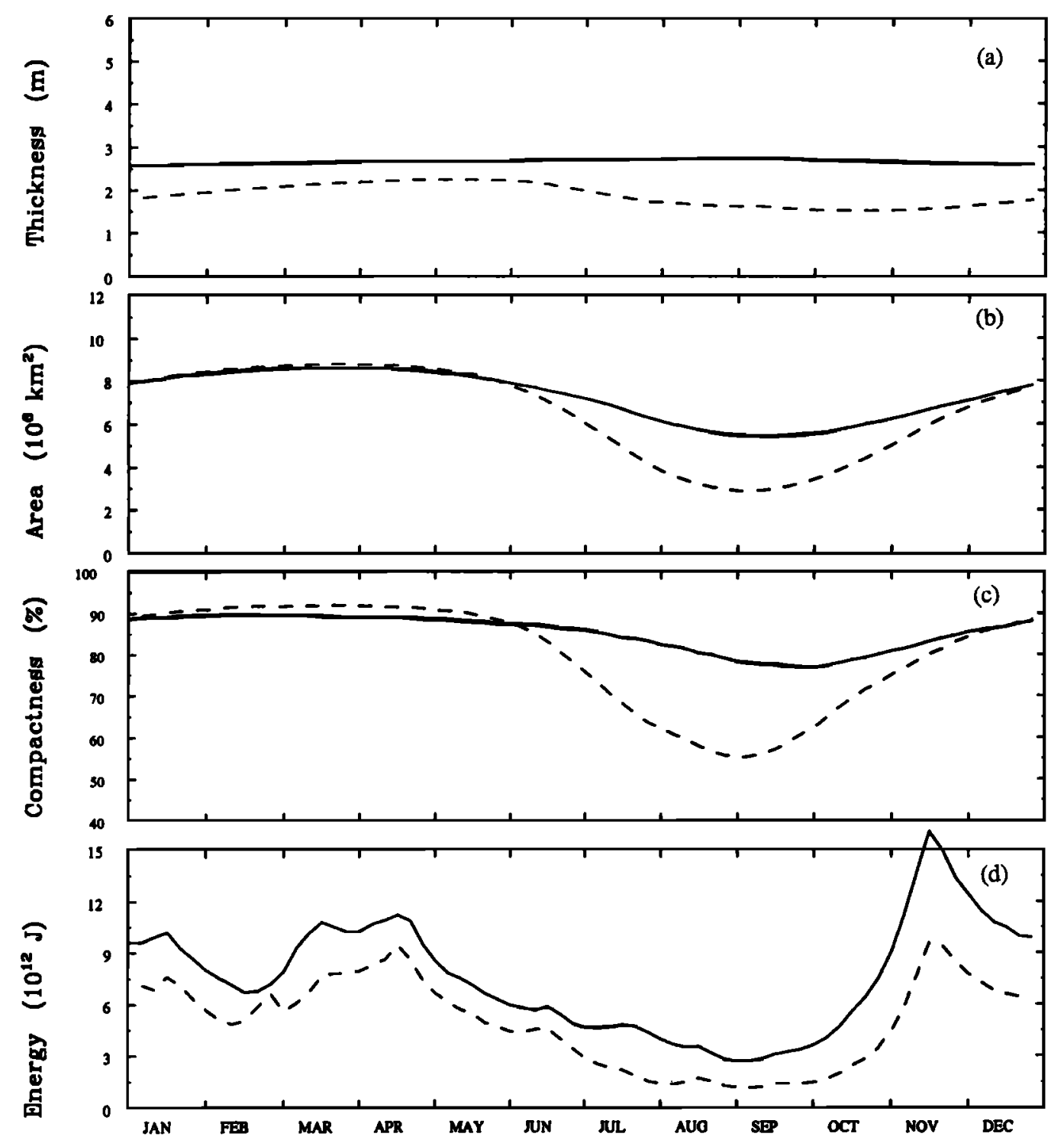

Fig. 18. Experiment $\mathrm{C} 17$ (snow cover). Time series of ice thickness, areal coverage, compactness, and kinetic energy over the equilibrium annual cycle. The dashed lines are the results from the control run.

thermodynamic model. This conclusion has also been noted by Owens and Lemke [1990]. In a modeling study of the Weddell Sea, they performed a sensitivity study in which they concluded that snow cover affects a thermodynamic sea ice model more than a dynamic thermodynamic model. They provided an interesting explanation for this phenomenon in terms of a negative feedback between the dynamics and the thermodynamics of the sea ice model. In regions where the thermodynamics reduces the ice thickness, the ice gets weaker and the dynamics (under favorable conditions, i.e., convergence) can readily increase the ice thickness (by importing ice into the region). In regions where the dynamics reduce the ice thickness (divergence), the thermodynamics (under favorable conditions, i.e., cooling) can easily increase the sea ice thickness. These interactions provide a negative, i.e., stabilizing feedback [Owens and Lemke, 1990].

Experiments C18 and C19: Changes in air temperature. It is interesting to study the response of the sea ice model to changes in atmospheric temperature that have been predicted, for example, from nuclear winter or from global warming experiments using coupled atmosphere-ocean models with a simple sea ice component [e.g., Manabe et al., 1991]. It is also important to keep in mind, however, that the simplistic experiments C18 and C19 can only identify the first-order response of sea ice to a hypothetical cooler or warmer Arctic. As such, they ignore other changes that would accompany cooler or warmer temperatures, such as changes in the atmospheric winds and precipitation.

The control run was forced with monthly fields of atmospheric temperatures. In the following experiments, uniform spatial changes through each month of the year were made to these fields. These changes in atmospheric temperature directly affect the calculation of downward longwave radiation, and the sensible and latent heat fluxes. These quantities, in turn, feed into the calculation of the total atmospheric heat flux $Q_{\text {air }}$, which appears in (4).

C18: Uniformly decreasing the atmospheric temperature by $5^{\circ} \mathrm{C}$ produces an approximate $40-\mathrm{cm}$ increase in sea ice thickness. There is also greater areal extent and compactness in the fall associated with the colder temperatures. The 


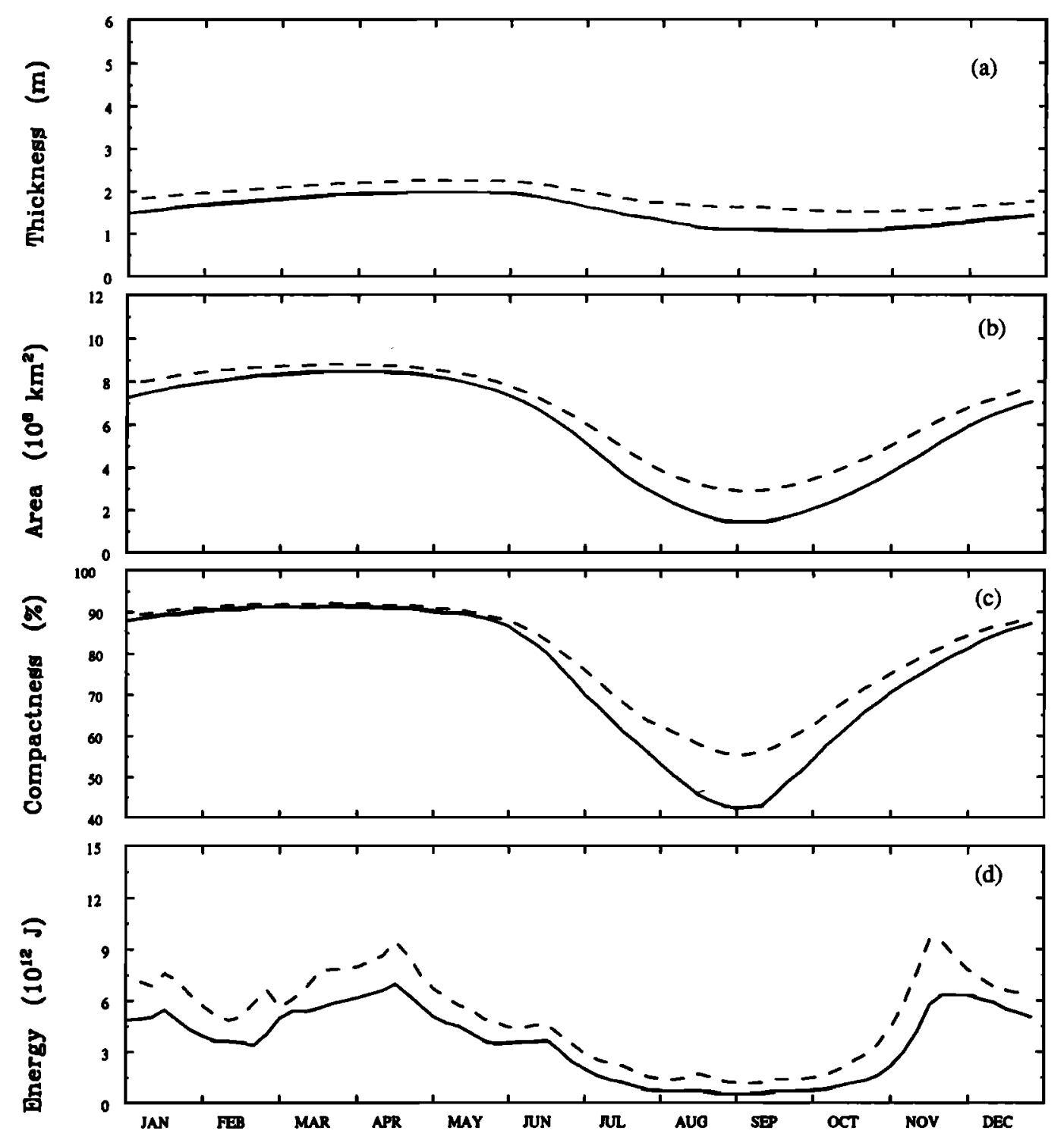

Fig. 19. Experiment C19 (air temperature). Time series of ice thickness, areal coverage, compactness, and kinetic energy over the equilibrium annual cycle. The dashed lines are the results from the control run.

ice surface temperature fields show a decrease of about $5^{\circ} \mathrm{C}$ in the central Arctic during winter.

C19: Uniformly increasing the atmospheric temperatures by $5^{\circ} \mathrm{C}$ produces the opposite effect. The reduction in ice thickness is approximately $40 \mathrm{~cm}$, yet the ice does not completely disappear at any time during the seasonal cycle (see Figure 19). Thus the ice pack is stable to perturbations in air temperature of $\pm 5^{\circ} \mathrm{C}$. Using a heat budget calculation for a given point in the central Arctic, Budyko [1966] determined that a positive anomaly of summer temperatures of only $4^{\circ} \mathrm{C}$ would cause ice of $4-\mathrm{m}$ thickness to melt completely after 4 years. Using a dynamic thermodynamic model with a more simplistic ice rheology than the one presented here, Parkinson and Kellogg [1979] found that the ice pack disappeared completely in August and September but reformed in the central Arctic in mid-fall. Semtner [1987] found that a $2^{\circ} \mathrm{C}$ increase was sufficient to cause a dramatic disappearance of the sea ice in late summer (Figure 20). He used a coupled ice-ocean model for his experiment. However, there are differences in the two sea ice models with respect to the rheology formulation, the number of layers for temperature, the coordinate system, and in the computation of net heat flux. As his integration was carried out for only a 2-year period, it cannot be expected that the imposed temperature increase would affect the ocean circulation; thus the only effect is on the thermodynamic aspects of the ice. Thus there is a noticeable difference in air temperature sensitivity between Semtner's sea ice model and the one presented here. It is difficult to speculate on the reasons for this difference; however, the subtle differences between each model's formulation of ice thermodynamics, dynamics, numerical methods, and atmospheric fields may be enough to account for the difference in results obtained.

\section{Conclusions}

This study has demonstrated that the Oberhuber spherical coordinate sea ice model produces a reasonable simulation of the seasonal cycle of sea ice in the Arctic. All the known major features of the seasonal cycle of ice thickness, com- 


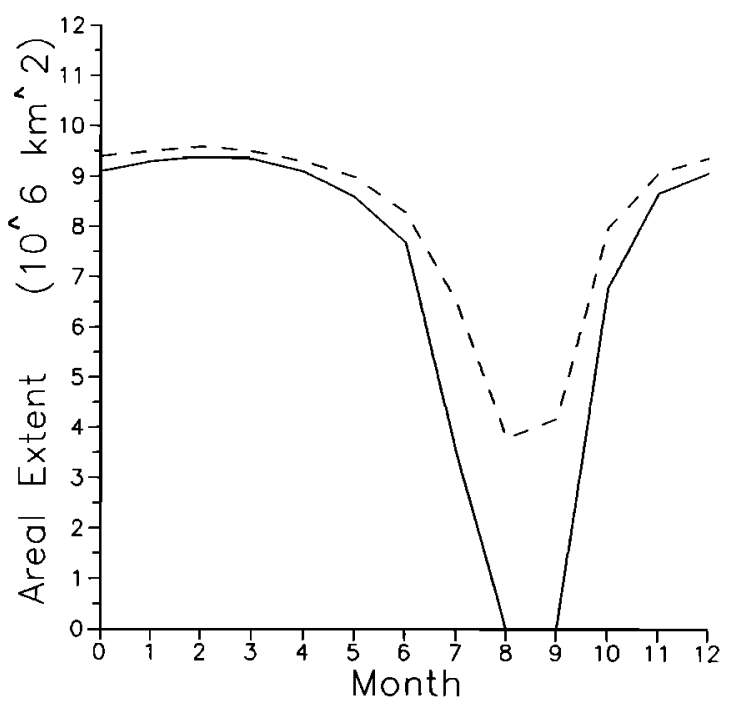

Fig. 20. Seasonal cycle of areal ice extent of Semtner [1987]. The solid curve indicates the case in which the atmospheric temperatures have been uniformly increased by $2^{\circ}$ everywhere. The dashed line represents the control run which includes the fully prognostic ocean model (redrawn from Semtner [1987]).

pactness, and velocity have been reproduced. Furthermore, a stable time integration is guaranteed by the appropriate choice of time step increment determined by the Courant condition and by the choice of a numerical diffusion coefficient estimated by the grid cell Reynold's number condition. Also, an appropriate value for the maximum bulk viscosity is given. The use of a predictor-corrector technique coupled with a semiimplicit scheme gives reliable and efficient convergence for the difficult nonlinear rheology terms in the ice equations.

An important objective of this study has been to carry out a thorough sensitivity analysis of a dynamic thermodynamic sea ice model. Although several of the sensitivity experiments have been carried out elsewhere, it is difficult to estimate the relative importance of various effects because different models have been used. By contrast, all the experiments done here use the same model, and the results are compared against one control run. Also, this study has examined the effect of certain processes and parameter variations that have not previously been carried out.

This sensitivity study has shown that the sea ice model produces a robust simulation of the seasonal cover of Arctic sea ice. Sensitivity studies have been presented under three different investigative themes, namely, numerical conditions, parameter variations, and physical processes. The results of these studies are summarized below.

The numerical condition experiments (theme A) show the model to be essentially insensitive to initial conditions. Upon spinning up from a motionless and ice-free Arctic, the model produces a reasonable simulation in the fifth year of integration. However, it was noted that when spinning up with the unrealistic ice thickness of $\mathbf{1 0} \mathrm{m}$ everywhere, the model did not reach equilibrium even after 10 years of integration. A second finding was that the choice of boundary condition at the model pole, where grid cells converge, is not crucial to the simulation. Thus the use of a spherical coordinate system with convergence at the pole does not adversely affect the simulation away from the poles. This suggests the presence of the model coordinate pole at the North Pole in a global simulation using the fully coupled Oberhuber ice-ocean model would not degrade the model's performance.

The parameters investigated relate to or include ice rheology, thermodynamic coefficients, diffusion coefficients, conductivity, albedo, drag coefficients, turbulent heat transfer coefficients, cloud fraction, emissivity, minimum fraction of leads, mixed layer salinity, depth, and turbulent heat flux. From this set of parameters, the model was found to be particularly insensitive to the mixed layer properties such as ocean albedo, salinity, and depth. The parameter that probably contains the greatest uncertainty is the cloud fraction, and changing it has drastic effects. An experiment with increased cloud cover, relative to the control run, leads to a more realistic seasonal ice simulation.

The final set of experiments dealt with the removal or addition (theme $\mathrm{C}$ ) of specific dynamic and thermodynamic processes. These experiments highlight the relative importance of the different components of the model. With regard to the heat budget, the latent heating was found to be a minor contributor to the overall budget; thus elaborate parameterizations of this process are unwarranted. Although the atmospheric winds make a greater contribution (70\%) to the ice kinetic energy than the ocean currents (30\%) [Thorndike and Colony, 1982], it is necessary to include both in the surface stress calculations. Using a bulk-viscous rheology, in which shear stresses have been eliminated, leads to more energetic ice circulation. The inclusion of the ocean surface tilt term in the momentum balance was not found to be important. Removal of the Coriolis force from the simulation displaces the ice velocity vectors about $10^{\circ}$ to the left of those in the control run. Completely eliminating the ice dynamics leads to an unrealistic simulation. Concerning heat storage within the ice, it was found that assigning the ice a realistic specific heat capacity (instead of zero) does not affect the simulation, but that the inclusion of brine pockets has a significant impact by delaying the onset of freezing during the fall. Including snowfall in the model was not felt to be crucial to the simulation.

Discrepancies have been noted between sensitivity studies carried out here and those carried out elsewhere. Maykut and Untersteiner [1971] found that in a thermodynamic-only model, sea ice thickness would increase uncontrollably if the snow fall exceeded $120 \mathrm{~cm} / \mathrm{yr}$; in this study the sea ice model was stable to annual snowfall rates as high as $200 \mathrm{~cm} / \mathrm{yr}$. Semtner [1976] reported that adding snow to a sea ice model introduces natural interannual oscillations in the sea ice cover with a 6-year period; no such interannual variation was found in this study. Regarding the ice rheology parameters, Hibler [1979] found that increasing the compressive strength substantially reduces the relative geographical ice thickness variations. Such a sensitivity was not noted here. Hibler also removed the ice compactness equation and found that the simulation does not change significantly. In this model, however, complete removal of this equation led to a drastic change in the simulation. Concerning cloud cover, Shine and Crane [1984] concluded that on an annual basis, clouds act to warm the surface and reduce the ice thickness. The opposite result was found in this study; clouds were found to cool the surface and to increase ice thickness. It is concluded that the competing effects of clouds on the radiation budget through longwave and shortwave radiation require further investigation in a three-dimensional dynamic 
thermodynamic sea ice model. Semtner [1987] obtained an ice-free Arctic during the month of September in an experiment in which he increased the atmospheric temperatures by $2^{\circ}$ everywhere. In the present study, a $5^{\circ}$ increase in temperature produced a significant decrease in all ice characteristics, but did not lead to an ice-free Arctic at any time during the seasonal cycle. Thus we wish to caution the reader against assuming these issues are settled. Further investigations with coupled atmosphere-ocean models are required to settle these open questions.

A technical weakness of the sensitivity tests is the absence of feedbacks to the prescribed forcing variables. For example, the specification of 5\% open water (experiment B37) would almost certainly increase the surface air temperatures to values above those now prescribed during the nonsummer months, thus leading to a greater impact on the ice than was obtained here. Similarly, snowfall (experiments C16 and C17) will alter the surface energy balance and the real world's surface air temperatures. A final example is experiment $B 21$, in which a drastic change in the ocean albedo is buffered in the model by the inability of the air temperature to change accordingly. Thus the real world (or even a coupled model) may respond quite differently than the artificially constrained model used here.

A major impediment to progress in sea ice modeling at present is the severe lack of observations to either validate or to assimilate into the models. The future increase in satellite observations will be helpful but will not provide all the measurements needed. Sea ice thickness data, for instance, are scarce over the Arctic, and the data that do exist are sporadic in both space and time. As another example, measurements of upward heat flux from the deep ocean, which is of paramount importance to a realistic simulation, are virtually nonexistent. The accuracy of simulations cannot progress until this situation is rectified.

This study has implications for atmospheric models that are coupled to a dynamic thermodynamic sea ice model in which the ocean is represented as a simple mixed layer. Mixed layer currents contribute significantly to the ice drift and cannot be ignored. Specification of seasonally and spatially varying mixed layer salinity or mixed layer depth is not important; specification of upward deep ocean heat flux is important. In particular, it is well known that it is the spatial and temporal variations in this heat flux that are crucial. It is unsatisfactory to specify this flux as a time and space invariant quantity.

Acknowledgments. The authors thank John Walsh, Knut Aagaard, Gordon Fleming, Greg Flato, William Hibler III, Achim Stössel, Martin Claussen, and Howard Cattle for helpful discussions on sea-ice modeling. The authors are also indebted to the referees for their many helpful comments which led to an improved manuscript. The authors are grateful for data supplied by John Walsh and William Chapman of the University of Illinois, Gordon Fleming of the Royal Roads Military College, Bonita Samuels of the Geophysical Fluid Dynamics Laboratory, and William Hibler III and John Ries of Dartmouth College. Ursula Seidenfuss is thanked for drafting some of the figures. The Ontario Centre for Large Scale Computing is acknowledged for computing time provided on their Cray X-MP and their excellent technical support. D.M.H. is grateful for graduate student support from the Newfoundland Government Career Development Awards Programme and the Atmospheric Environment Service. L.A.M. is grateful for research support from the Atmospheric Environment Service, the Natural Sciences and Engineering Research Council, and the U.S. Office of Naval Re- search. J.M.O. is grateful for support from the European Community and the Bundesminister für Forschung und Technologie.

\section{REFERENCES}

Anderson, R. J., Wind stress measurements over rough ice during the 1984 Marginal Ice Zone experiment, J. Geophys. Res., 92, 6933-6941, 1987.

Bourke, R. H., and R. P. Garrett, Sea ice thickness distribution in the Arctic Ocean, Cold Regions Sci. Technol., 13, 2107-2117, 1987.

Budyko, M. I., Polar ice and climate, in Soviet Data on the Arctic Heat Budget and Its Climatic Influence, edited by J. O. Fletcher, B. Keller, and S. M. Olenicoff, pp. 9-24, Rand Corporation, Santa Monica, Calif., 1966.

Colony, R., Seasonal mean fields of ice motion in the Arctic Basin, Polar Science Centre Report, University of Washington, Seattle, Aug. 1991.

Flato, G. M., and W. D. Hibler III, On modelling pack ice as a cavitating fluid, J. Phys. Oceanogr., 22(6), 626-651, 1992.

Fleming, G. H., An examination of the ice-control mechanisms in a coupled ice-ocean numerical model of the Arctic, Coastal Mar. Sci. Lab. Rep. 90-2, 59 pp., Royal Roads Military College, Victoria, B. C., 1990.

Hibler, W. D., III, A dynamic thermodynamic sea ice model, $J$. Phys. Oceanogr., 9, 815-846, 1979.

Hibler, W. D., III, Modeling a variable thickness sea-ice cover, Mon. Weather Rev., 108, 1943-1973, 1980.

Hibler, W. D., III, and K. Bryan, A diagnostic ice-ocean model, $J$. Phys. Oceanogr., 17, 987-1015, 1987.

Holland, D. M., L. A. Mysak, and J. M. Oberhuber, Simulation of the seasonal Arctic sea ice cover with a dynamic thermodynamic sea ice model, Res. Rep. 91-17, 68 pp., Cent. for Clim. and Global Change Res., McGill Univ., Montréal, Québec, $1991 a$.

Holland, D. M., L. A. Mysak, and J. M. Oberhuber, Sensitivity study of a dynamic thermodynamic sea-ice model, Res. Rep. 91-22, 400 pp., Cent. for Clim. and Global Change, McGill Univ., Montréal, Québec, $1991 b$.

Huschke, R. E., Arctic cloud statistics from air calibrated surface weather observations, Memo. RM-5003-PR, Rand Corp., Santa Monica, Calif., 1969.

Idso, S. B., and R. D. Jackson, Thermal radiation from the atmosphere, J. Geophys. Res., 74, 5397-5403, 1969.

Laevastu, T., Factors affecting the temperature of the surface layer of the sea, Commentat. Phys. Math., 25(1), 1960.

Manabe, S., R. J. Stouffer, M. J. Spelman, and K. Bryan, Transient responses of a coupled ocean-atmosphere model to gradual changes of atmospheric $\mathrm{CO}_{2}$, Part I, Annual mean response, $J$. Clim., 4, 785-818, 1991.

Marashunova, M. S., Principal characteristics of the radiation balance of the underlying surface and of the atmosphere in the Arctic, in Soviet Data on the Arctic Heat Budget and Its Climatic Influence, edited by J. O. Fletcher, B. Keller, and S. M. Olenicoff, pp. 51-131, Rand Corporation, Santa Monica, Calif., 1966.

Maykut, G. A., and N. Untersteiner, Some results from a time dependent, thermodynamic model of sea ice, J. Geophys. Res., $76,1550-1575,1971$.

Oberhuber, J. M., Simulation of the Atlantic circulation with a coupled sea ice-mixed layer-isopycnal general circulation model, Rep. 59, 86 pp., Max-Planck-Inst. for Meteorol., Hamburg, 1990. (Also in modified form, J. Phys. Oceanogr., in press, 1992.)

Owens, W. B., and P. Lemke, Sensitivity studies with a sea ice-mixed layer-pycnocline model in the Weddell Sea, J. Geophys. Res., 95, 9527-9538, 1990.

Parkinson, C. L., and W. M. Kellogg, Arctic sea ice decay simulated for a $\mathrm{CO}_{2}$-induced temperature rise, Clim. Change, 2, 149-162, 1979.

Parkinson, C. L., and W. M. Washington, A large-scale numerical model of sea ice, J. Geophys. Res., 84, 311-337, 1979.

Parkinson, C. L., C. J. Josefino, H. J. Zwally, D. J. Cavalieri, P. Gloersen, and W. J. Campbell, Arctic sea ice 1973-1976: Satellite passive microwave observations, NASA Spec. Publ., SP-489, 296 pp., 1987.

Press, W. H., B. P. Flannery, S. A. Teukolsky, and W. T. Vetterling, Numerical Recipes: The Art of Scientific Computing, 818 pp., Cambridge University Press, New York, 1988. 
Roach, P. J., Computational Fluid Dynamics, 446 pp., Hermosa, Albuquerque, N. M., 1985.

Ross, B., and J. E. Walsh, A comparison of simulated and observed fluctuations in summertime Arctic surface albedo, J. Geophys. Res., 92, 13,115-13,125, 1987.

Semtner, A. J., Jr., A model for the thermodynamic growth of sea ice in numerical investigations of climate, J. Phys. Oceanogr., 6, 379-389, 1976.

Semtner, A. J., Jr., A numerical study of sea ice and ocean circulation in the Arctic, J. Phys. Oceanogr., 17, 1077-1099, 1987.

Shine, K. P., and R. G. Crane, The sensitivity of a one-dimensional thermodynamic sea ice model to changes in cloudiness, J. Geophys. Res., 89, 10,615-10,622, 1984.

Thorndike, A. S., and R. Colony, Sea ice motion in response to geostrophic winds, J. Geophys. Res., 87, 5845-5852, 1982.

Washington, W. M., A. J. Semtner, C. L. Parkinson, and L. Morrison, On the development of a seasonal change sea ice model, J. Phys. Oceanogr., 6, 679-685, 1976.
Zillman, J. W., A study of some aspects of the radiation and heat balance of the southern hemisphere oceans, Meteorol. Stud. 26, 562 pp., Bur. of Meteorol., Dep. of the Interior, Canberra, Australia, 1972.

D. M. Holland and L. A. Mysak, Centre for Climate and Global Change Research, McGill University, 805 Sherbrooke Street West, Montréal, Québec H3A 2K6, Canada.

D. K. Manak, Canada Centre for Remote Sensing, Ottawa, Ontario, Canada.

J. M. Oberhuber, Meteorology Institute, University of Hamburg, Bundesstrasse 55, 2000 Hamburg 13, Germany.

(Received February 19, 1992; revised August 5, 1992; accepted August 17, 1992.) 